







LA

VENTE HAMILTON 
TIRAGE A CINQ CENTS EXEMPLAIRES

$$
\begin{aligned}
& \mathrm{N}^{\text {os }} \text { I à } 20 \text { sur papier du Japon. } \\
& 2 \text { I } 50 \text { sur papier de Hollande. } \\
& 8 \text { I } 500 \text { sur papier fort. }
\end{aligned}
$$

Il a été tiré en outre cinquante exemplaires non numérotés, chacun portant le nom de la personne à laquelle il aura été offert.

$$
\text { Exemplaive } N^{\mathrm{O}} \mathrm{Q}
$$





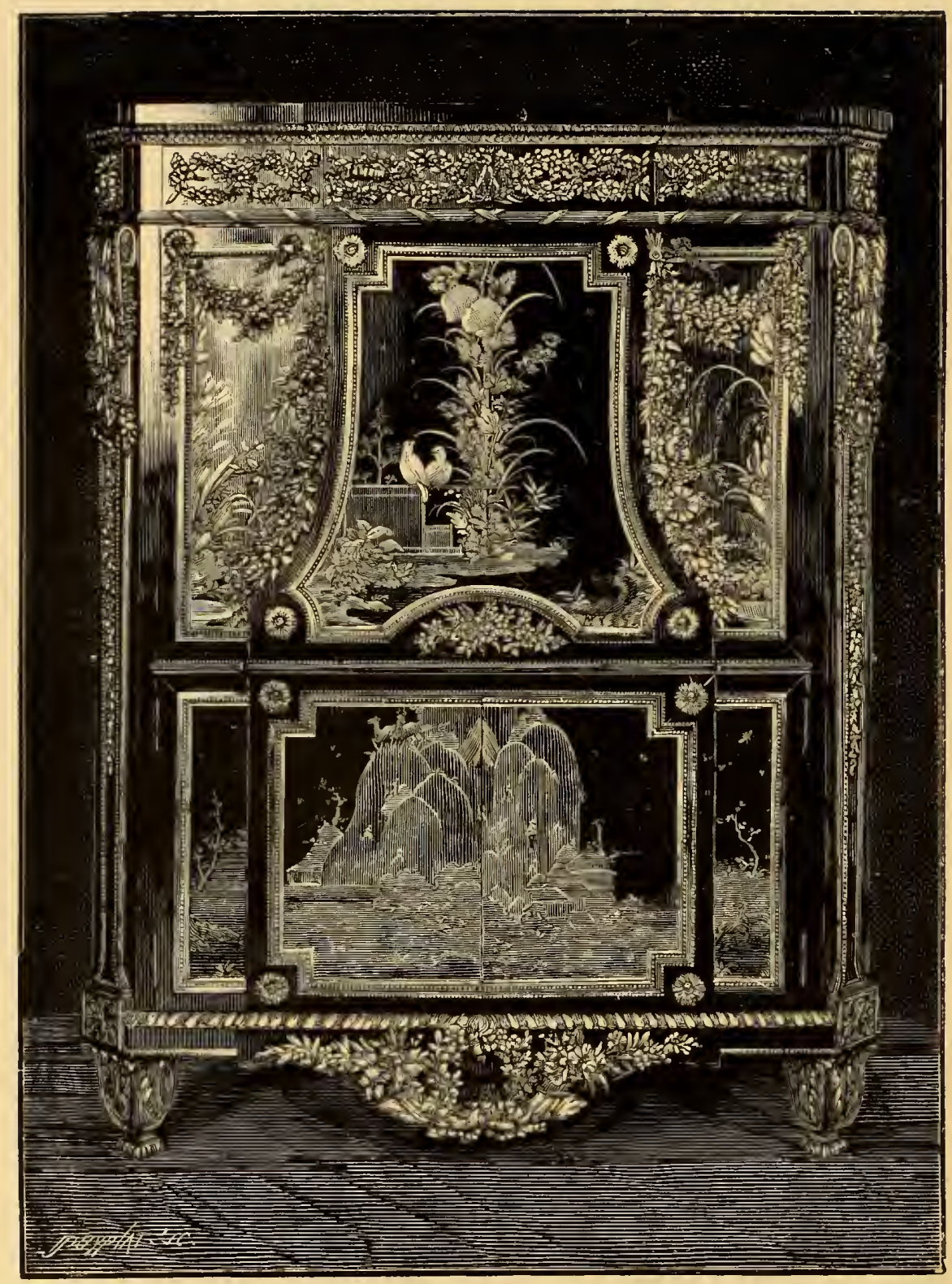

$N^{*}$ 1297. - Secrétaire Louis XVI de Gouthière (vendu $24^{5} 700$ fr.). 
$N$

5247

+135
1283

\title{
PAUL EUDEL
}

\author{
L A
}

\section{VENTE HAMILTON}

$$
\text { A VEC }
$$

VINGT-SEPT DESSINS HORS TEXTE

$$
\text { PAR IS }
$$

G. CHAR PENTIER, É D I TEUR

I3, RUE DE GRENELLE SAINT-GERMAIN

I $\$ 83$ 



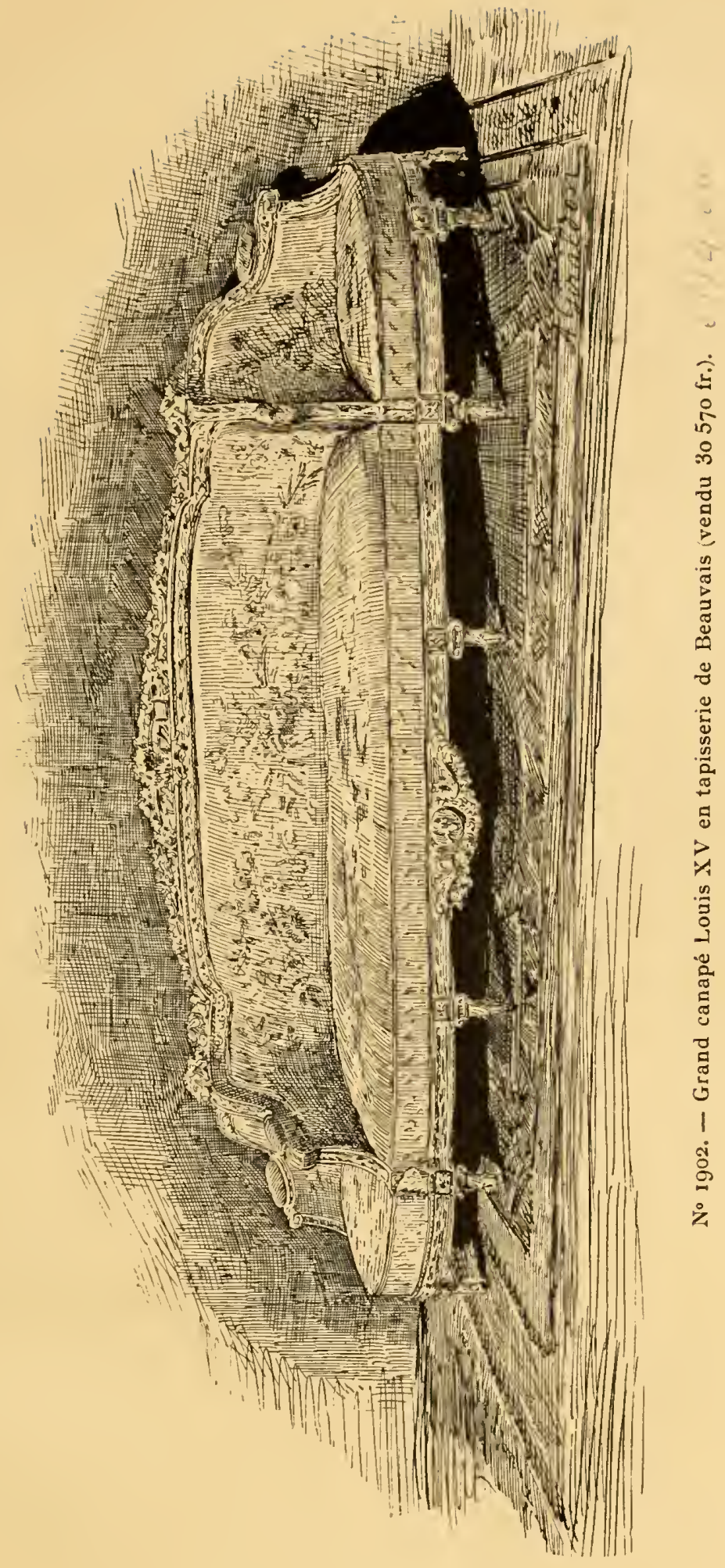





\section{VENTE HAMILTON}

\section{I}

- Cocher, à la gare du Nord.

Et le fiacre, contrairement à ses habitudes, file comme une flèche et me dépose dix minutes après sur le trottoir de la place Roubaix.

J'entre dans la salle; je vais au guichet prendre mon billet, un cahier à plusieurs feuillets.

— Tiens! Mannheim, Chevallier, Guénot, Michel, Bourgeois, font déjà enregistrer leurs bagages.

Nous partons tous pour Londres. C'est l'hôtel Drouot qui se met en wagon afin d'aller soutenir l'honneur du pavillon français à la vente Hamilton. Les uns chargés de commissions, d'autres avec de gros chèques dans leurs portefeuilles pour faire des achats, d'autres enfin, comme moi, non pour entrer dans l'arène, mais pour étudier de près, en simple spectateur, la physionomie des ventes anglaises. 
L'heure du départ sonne bientôt.

- En voiture! messieurs les voyageurs, en voiture!

Nous nous groupons tous ensemble. Nous parlerons de nos projets : le voyage sera ainsi moins long.

La locomotive glisse d'abord doucement sur les rails, puis sa vitesse s'accélère peu à peu. Saint-Denis, Creil et ses fabriques passent rapidement devant nous.

Amiens! Quinze minutes d'arrêt! Pas le temps d'aller voir la cathédrale gothique!

Abbeville! Une vision cachée dans la fumée. Elle est déjà loin. La voie court dans la charmante vallée de la Somme, et nous sentons l'air vivifiant du bord de la mer.

Voici Boulogne avec sa colonne de la grande armée qui s'élève à cent cinquante pieds de hauteur. Le train passe près de l'embouchure de la petite rivière de la Liane, s'arrête sur le quai encombré de pêcheuses en jupons courts et de marins lourds, nerveux et râblés autant que des sangliers.

Le paquebot l'Alexandra est là qui nous attend dans le bassin, jetant en l'air des torrents de fumée. Nous retrouvons d'autres voyageurs, MII. Cernuschi, Sichel, Stettiner, Warneck, Beurdeley fils, Arnold Tripp, Eugène Lecomte et Gauchez, l'aimable et savant directeur de l'Art. Comme nous, ils vont au grand congrès anglais. Décidément la lutte sera chaude, car le continent envoie en Angleterre ses meilleures réserves.

L'Alexandra se met en route. Sous les roues qui la frappent, l'eau jaillit en écume. La mer est forte et 
houleuse, la cime des lames surmontée d'une crinière blanche, le ciel chargé de nuages. Tandis que nous mettons le nei dans la plume, comme disent les marins, chacun se prépare à la traversée. Quelques-uns s'assoient bravement près du timonier sur la dunette, la figure exposée aux âpres baisers de la brise, comme pour narguer le mal de mer. Plusieurs, n'osant affronter ce terrible compagnon de voyage, prêts au contraire à lui payer leur tribut, s'adressent au steward et se retirent prudemment dans une cabine.

Mais nous sommes en pleine mer. Rien n'y manque, roulis et tangage, embruns et coups de mer, parfums et trépidations de la machine. Ceux qui ont le pied marin se rient des malades : ils les engagent à demander au capitaine de faire installer des béquilles pour appuyer le navire.

Le cap Gris-ne; se découpe à l'horizon, puis s'efface dans un lointain bleuâtre, tandis que se dessinent bientôt les falaises jaunâtres des côtes anglaises. Folkestone apparaît avec ses maisons grises et ternes.

Nous débarquons au milieu d'une haie de curicux. Il y a bien quelques visages un peu blêmes, mais en général on s'est bien comporté. Le cœur a été solide.

Les bagages doivent être visités à Londres; aussi sur le quai pas de douanier qui vous jette, comme en France, des regards d'amère défiance. Nous montons dans un wagon-salon que, par une délicate attention, l'un d'entre nous, très habitué à ce voyage sur la route du South-Eastern railwaj, a fait retenir pour la colonie française. Très confortables avec leurs délicates 
attentions. Ce n'est pas comme à Londres où, si l'on a inventé le mot water-closets, on n'a guère créé la chose.

Le chef de gare fait sonner le départ, et le mécanicien se dispense du strident coup de sifflet qui vous écorche d'ordinaire les oreilles. En peu de temps nous prenons notre allure: une vitesse de quinze lieues à l'heure. La route est monotone, peu de pittoresque. Des tunnels et de grands pâturages avec beaucoup de moutons et de bestiaux. Les Anglais ont, pour les céréales, le monde entier comme grenier; ils ne font que de la viande. Et Londres fait tuer par an 400000 bœufs et 2 millions de moutons pour se nourrir.

Voilà Ashford et les grands ateliers de la Compagnie du chemin de fer; Tumbridge, Penshurt au milieu d'un grand parc; Edenbridge, Godstone, vus de loin des mirages!

Le beau temps pour aller à Londres! c'est la saison! (season). Le parlement siège, Hyde-Park est resplendissant. Tous les théâtres attirent à eux les premiers acteurs du monde. La Royal Academy fait son exposition annuelle.

Bientôt apparaît Sydenham avec son immense palais de cristal, Les chaumières deviennent des cottages, les maisons se multiplient. Nous traversons un épais brouillard de charbon de terre. De tous côtés se lisent de grandes affiches aux couleurs violentes. Nous entrons dans le pays de la réclame, nous sommes à Londres! Saluez la ville qui compte plus d'Écossais qu'à Édim- 
bourg, plus d'Irlandais qu'à Dublin, plus d'israélites qu'en Palestine, et plus de catholiques qu'à Rome.

Le train suit un haut viaduc qui traverse le faubourg des prolétaires, franchit la Tamise à London-Bridge, s'arrête à la station de Camon-street, revient en arrière, traverse deux fois encore le fleuve, et nous conduit à la grande gare vitrée de Charing-Cross.

Chacun s'apprête à gagner son hôtel, car les goûts sont très divisés, et nous n'avons pu, pendant la route, nous mettre d'accord.

- Où descendez-vous, Messieurs?

- A Charing-Cross Hotel.

- C'est un grand capharnaüm où l'on devient un numéro.

- Où allez-vous?

- A Royal Hotel.

- C'est trop près des odeurs de la Cité.

- Et vous?

- Chez $\mathrm{II}^{\mathrm{me}}$ Dieudonné, nous avons nos chambres préparées. Nous y retrouverons la Comédie-Française.

On hèle les cabs et l'on se quitte:

Beware the pick-pockets! Good bjee!

Nous sommes déjà à moitié Anglais.

Le grand rendez-vous est pour le lendemain, troisième jour d'exposition des collections Hamilton, chez MM. Christie Mansonand Woods at their great rooms, King street, Saint-James square, tout pres de la maison que Louis-Napoléon habitait avant la révolution de février. 



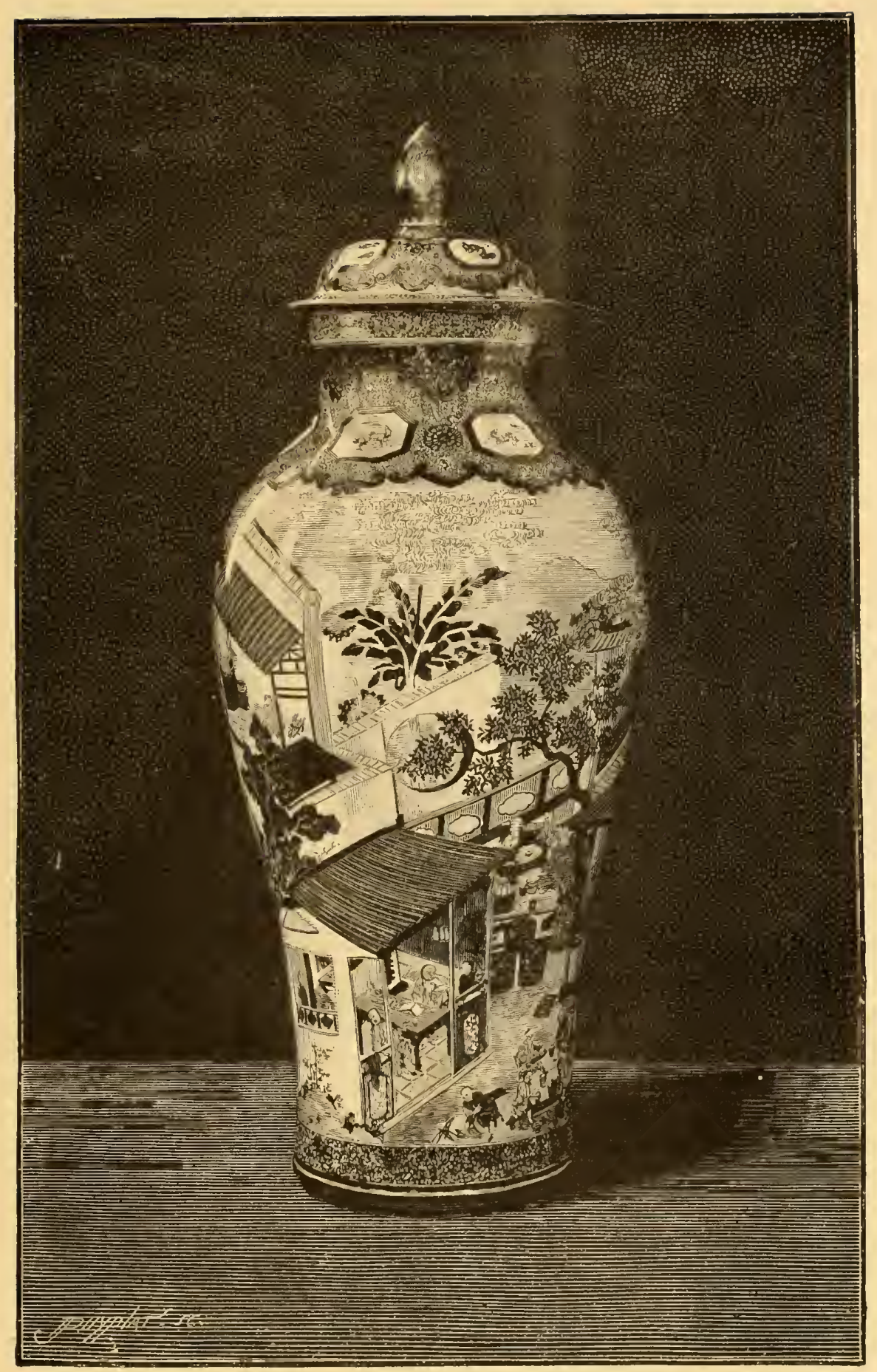

$\mathrm{N}^{*} 466$. - Vase de Chine « Mandarin " la paire vendue 15 (6go (r.) 



\section{II}

La vente Hamilton, ce grand tournoi artistique, se divise en cinq parties. Trois jours d'exposition, mercredi, jeudi et vendredi; puis trois jours de vente, samedi, lundi et mardi. C'est l'usage de vendre les tableaux le samedi. Ne me demandez pas trop pourquoi. Pendant la journée du dimanche on laisse réfléchir les acheteurs pour reprendre la vente le lundi. Ce qu'il y a de plus précieux est toujours réservé pour la fin des vacations. Le degré d'enthousiasme 'est ainsi savamment ménagé.

Dès neuf heures, grande réunion aristocratique chez les célèbres auctioneers, dans Piccadilly. Autour de la porte se promènent, revêtues d'une sorte de chasuble, des affiches ambulantes. C'est une belle occasion de faire de la réclame devant cette foule qui aime les beaux-arts. Il ne faut rien négliger; je note au hasard quelques-unes de ces annonces portées par de pauvres diables :

Munkacsy.

Great picture Christ before Pilate at conduct streel (Regent street). 
The Lion at home.-Chef-d'œuvre.-Rosa Bonheur.

Open from ten till six.

L. H. Lefevire's Gallery. I, King street, Saint-James.

Je passe sous silence : la Mare de Millet et les Convulsionnaires de Tanger par Delacroix, qui exhibent également leurs écriteaux. Il y a décidément une forte concurrence pour attraper quelques shillings au public.

Chez Christie, c'est une cohue. On se presse à s'étouffer dans les trois grandes salles de l'exposition. Il est bien difficile de voir à son aise. Promenons-nous! - Laissant de côté, provisoirement, les objets d'art, je regarae autour de moi les visiteurs que me nomme un ami compiaisant : la duchesse d'Édimbourg, lady Ashburton, le duc d'Albany, le comte et la comtesse de Roseberg, lady Charlotte Schreiber, le comte de Coventry; tous les Rothschild, de Vienne, de Francfort, de Paris et de Londres; le duc et la duchesse de Cleveland; Bohn, le vétéran des bibliophiles, âgé de quatre-vingt-six ans, et le richissime Christophe Beckett Denizon, qui doit faire de nombreux achats.

Quelques Anglaises, sans doute de l'aristocratie, très gracieuses et très bien mises, me paraissent des Parisiennes élégantes; mais que dire des autres, ladies rousses et misses blondes avec de grandes dents ou des toilettes du plus mauvais goût, des tailles qui descendent au talon pour rejoindre des pieds impossibles, aux chaussures invraisemblables. Ce sont celles-là seu- 


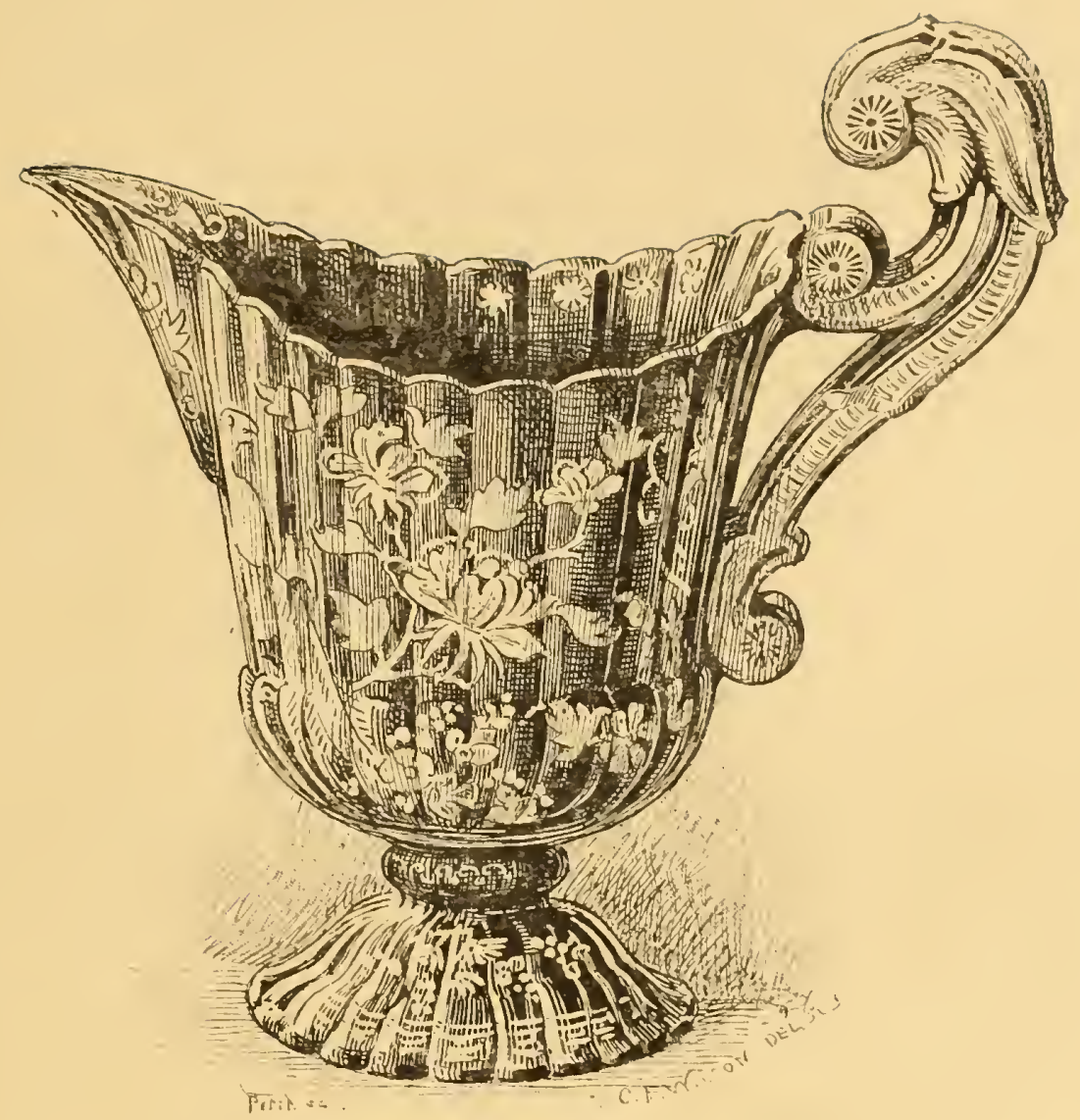

$\mathrm{N}^{\circ}$ 9o3. - Casque en faïence de Nevers vendu 5 t6o fr.). 

lement, à la démarche dansante, que nous rencontrons à Paris se promenant de l'Opéra à la Madeleine. Nous n'avons qu'une fausse idée de l'Anglaise. Il y en a d'adorablement jolies, mais il faut venir à Londres pour les voir.

Les hommes ont une tenue correcte; s'ils viennent à l'Opéra chez nous, en veston et en petit chapeau, chez eux, ce sont des gentlemen d'une extrême élégance. Ils se condamnent à perpétuité à la redingote, et se tiennent raides avec une rose à la boutonnière.

Je demande le petit catalogue des trois premières journées, afin de pouvoir comparer l'objet avec la description - deux choses qui se regardent quelquefois avec étonnement.

- Price, one shilling.

- Et le grand catalogue illustré?

- Price, one guinea (26 fr. 5o).

Rien pour rien. - Décidément tout est profit ici, L'Anglais est un marchand, ne l'oublions pas. 



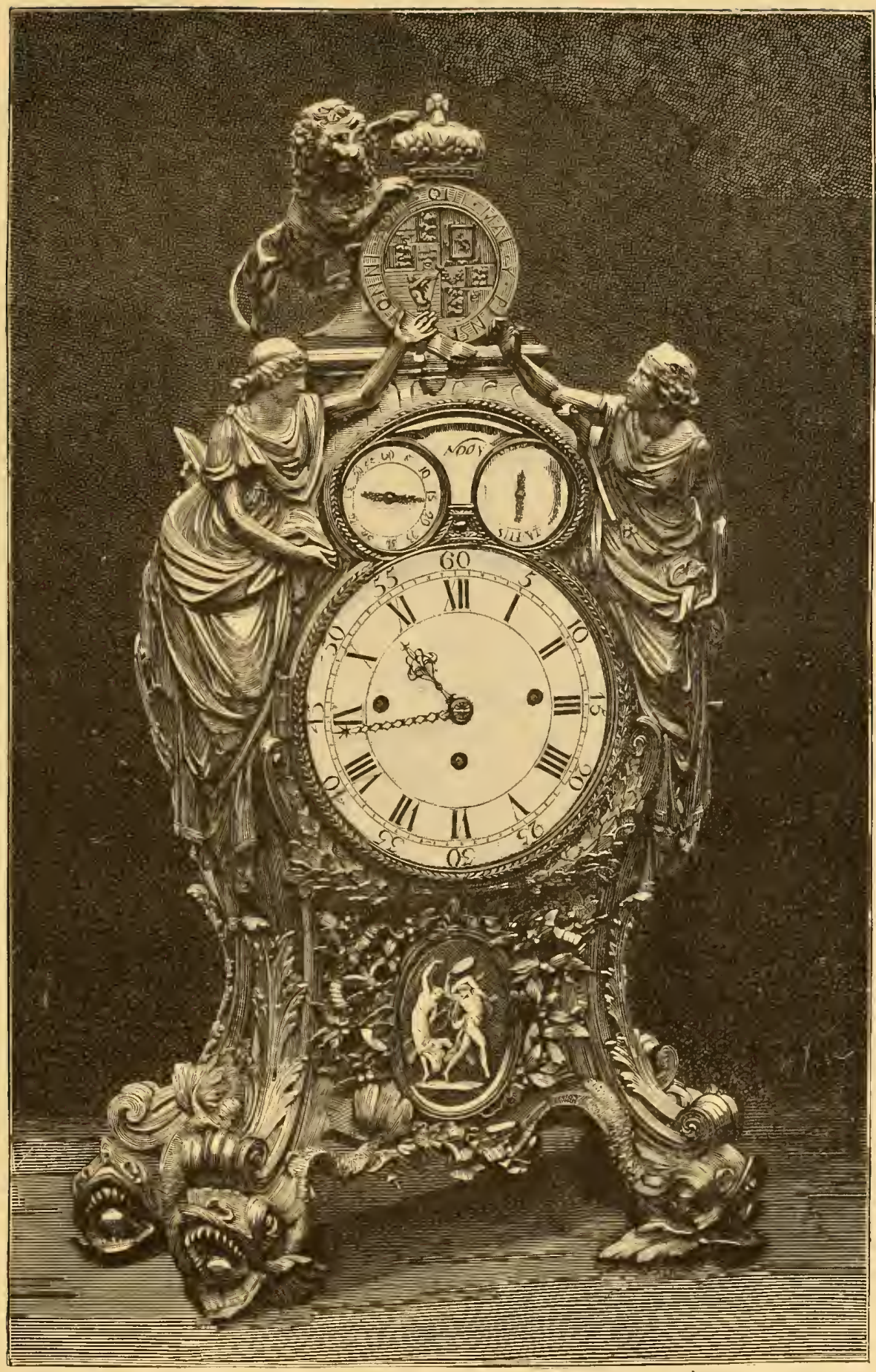

No $88_{4}$ - Pendule à cariilon (vendue 22386 fr. ). $\quad 4>i$ 



\section{I I}

Les ventes anglaises ne ressemblent nullement aux nôtres. Elles sont libres, par conséquent pas surchargées de formalités et de difficultés comme en France. $\mathrm{Ni}$ crieur, ni commissaire-priseur, ni experts, ni enregistrement, ni bourse commune. Il n'y a qu'un courtier en objets d'art qui ouvre boutique, et n'étant pas un magistrat, agit dans sa liberté absolue, sans garantie et sans responsabilité. Le vendeur lui paie 7 I/2 pour I oo pour ses peines et soins; il ne reçoit rien de l'acheteur en sus du prix d'adjudication, mais cet entrepreneur a soin de se garer de tous les risques, par des conditions de paiement si bien stipulées à l'avance, qu'elles vont même jusqu'à mentionner un versement de cinq shillings par livre, sitôt l'adjudication prononcée, ou la totalité de l'achat, si tel est son bon plaisir.

L'auctioneer n'accepte que des enchères d'un shilling, et sur cinq livres ne laisse pas mettre moins de cinq shillings et ainsi de suite. Il se réserve la faculté de surenchérir, lui-même s'il ne trouve pas l'objet arrivé à son prix.

Bien entendu, l'authenticité des objets n'est point garantie, - c'est plus prudent, - vous avez tout le 
temps de les examiner à l'exposition, de vous renseigner et de prendre un parti. Libre à vous de ne rien traiter. Si vous achetez et si vous le regrettez ensuite, tant pis pour vous. Aucune réclamation n'est possible.

C'est sur ces bases, en usage depuis longues années, que doit se faire la vente des collections qui nous occupent. Le moment est venu de dire quelques mots sur ceux qui les ont formées.

Ce n'étaient point de petits compagnons, comme disait Henri IV, ces Hamiltons issus d'une branche cadette des Leicester. Ils ont joué un rôle considérable dans l'histoire d'Angleterre. On pourrait refaire avec cux la tirade d'Hernani. L'un d'eux fut déclaré héritier présomptif du trône d'Écosse à la mort de Jacques $V$. Un autre fut tué dans un duel célèbre en I7I2, à Hyde-Park, par lord Mohun, qui resta également sur le pré. Un autre fut fait prisonnier par Cromwell à la bataille de Worcester. Un autre resta longtemps l'ami du duc de Grammont. Le père du duc actuel, mort après souper dans un cabinet de la Maison d'or, avait épousé la fille de Stéphanie de Beauharnais.

Le lord, qui chambarde en ce moment toute sa collection, comme a écrit Albert Wolff, fut Parisien pendant quelque temps. Avant i 870 , le turf l'absorbait : il ne vivait que pour les chevaux. Depuis, il est retourné en Angleterre, ne faisant plus que de courtes apparitions chez nous. La vie politique l'absorbait.

Maintenant le duc Hamilton veut, pour exploiter des mines de charbon, démeubler d'abord le vieux manoir de ses pères, une masse imposante de granit, 


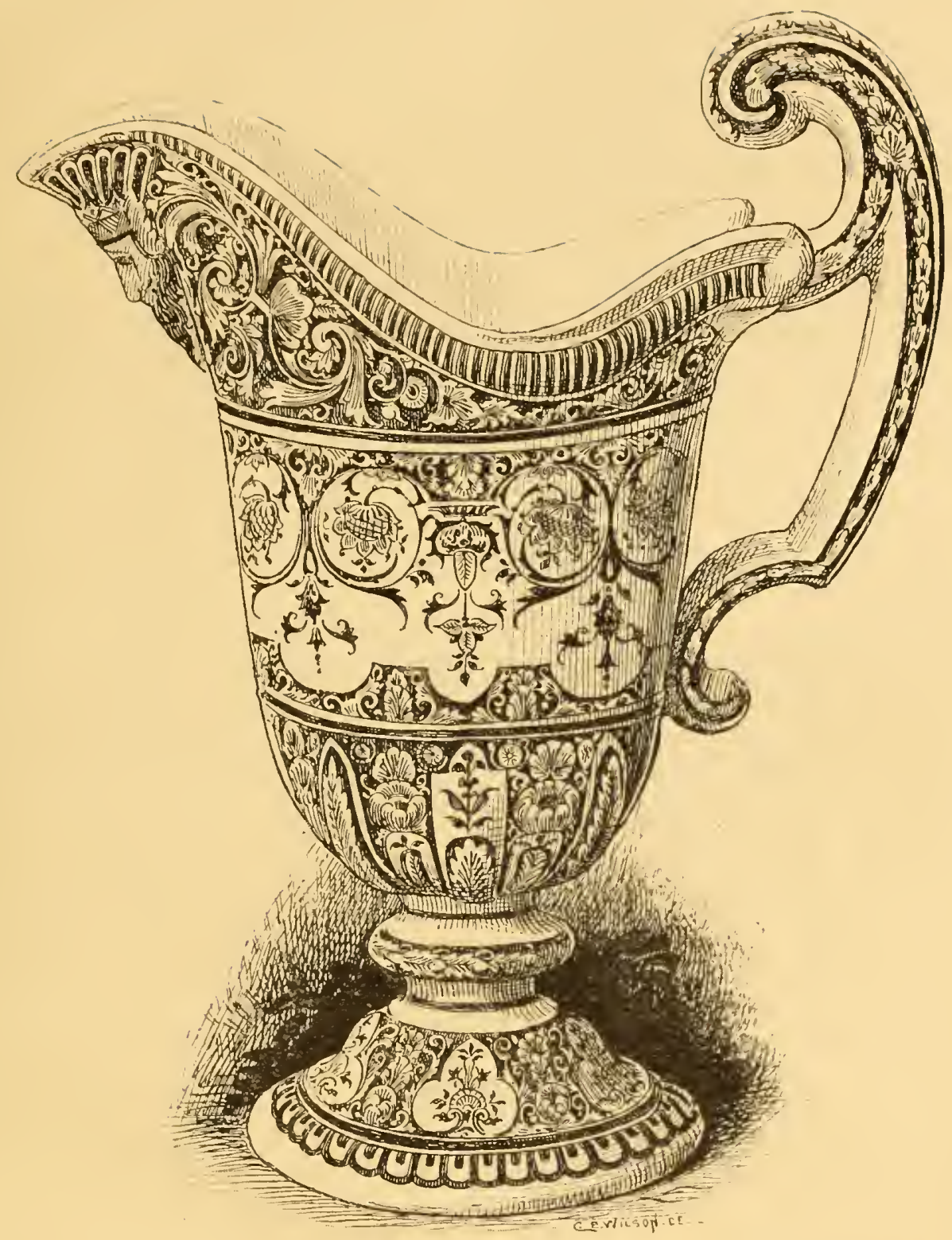

N. gry. - Casque en faïence de Rouen (vendu 3 g5: fr.). 

tout près de Glascow, à deux pas de ce vieux chàteau de Châtellerault, qui a fourni à Walter Scott le sujet d'une de ses ballades. Le dernier de la race le fera raser ensuite sans doute, car il paraît préférer aux richesses artistiques, qui ne rapportent rien, les richesses minérales, qui peuvent rapporter beaucoup. Auri sacra fames. Mais il a dû demander une loi à la Chambre des lords pour pouvoir aliéner son majorat, et se séparer de ses collections, qui faisaient de lui un grand seigneur, tenant une place considérable dans la curiosité, comme sir Richard Wallace et le duc d'Aumale. Il ira jusqu'au bout, et quand on aura commencé à creuser le sol, il fera transporter dans son île d'Arran le mausolée de ses ancêtres, qui peut rivaliser de richesse avec celui érigé par la reine Victoria à Windsor.

La collection est estimée à un million de livres sterling (25 millions de francs), en y comprenant les tableaux, objets d'art, et les deux bibliothèques : Hamilton library et Bechford library, cette dernière formée par William Beckford, le bisaïeul du lord actuel, dont la fille unique, en épousant le duc Hamilton, a fait entrer ses richesses dans la maison de Douglas.

Tout ne doit pas être vendu cependant; quelques souvenirs seront respectés : le portrait du premier duc par van Dyck; le berceau de la reine Élisabeth, et la bague d'or et de saphirs que l'infortunée Marie Stuart envoya, la veille de son exécution, au duc d'Hamilton, qui avait été, pendant sa minorité, régent du royaume d'Écosse. 



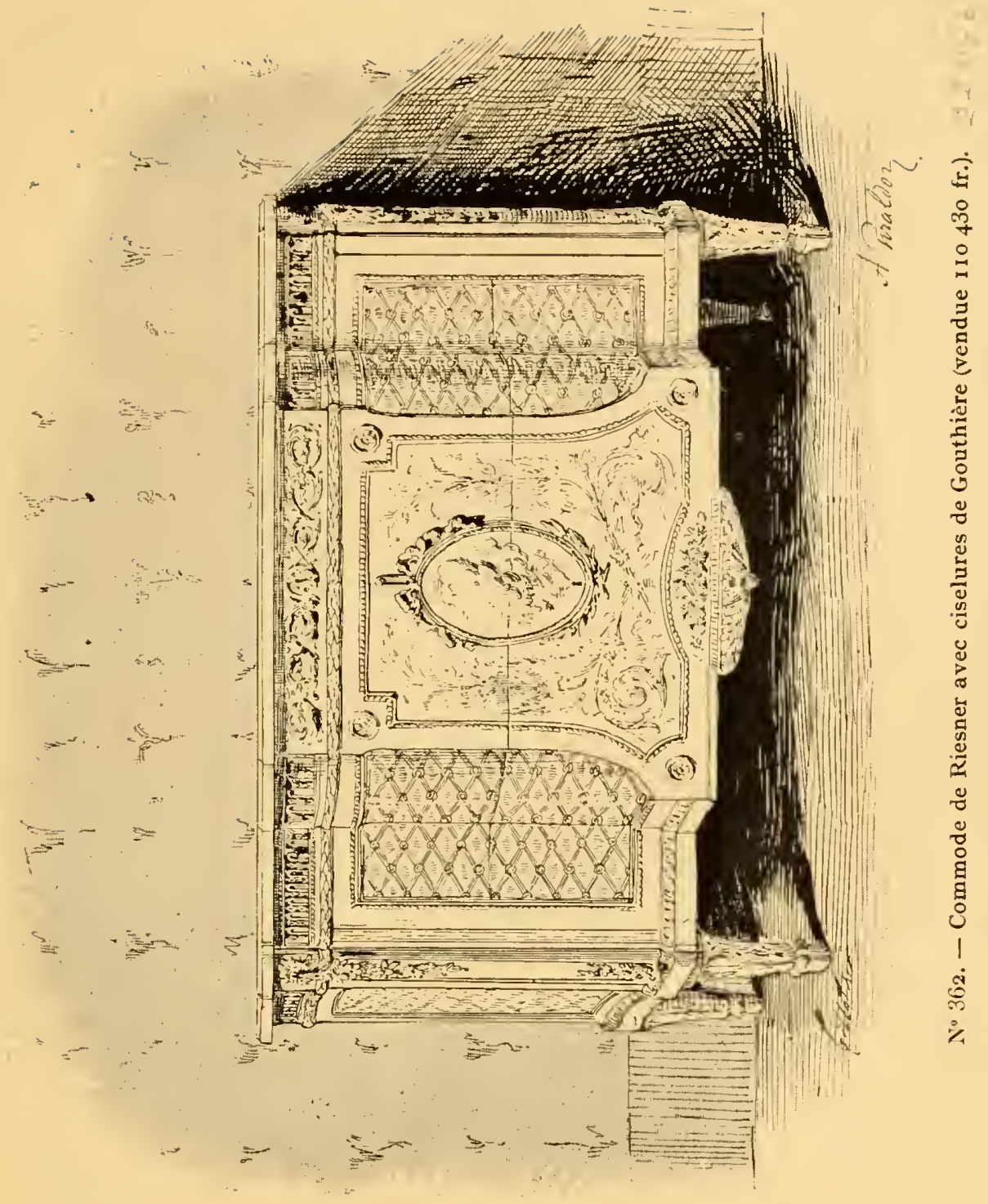





\section{V}

Mais nous étions chez Christie, le catalogue à la main, cherchant à passer en revue, comme à l'hôtel Drouot, les trois cents numéros de la première exposition. Nous retrouvons là, venus comme nous du continent, depuis plusieurs jours sans doute, M. Leroy de Bruxelles, accompagné de $\mathbf{M}$. Schubert, le délégué du gouvernement belge; Sedelmeyer, le grand marchand de tableaux; Barre, le sémillant expert; Rutter, de Paris; Strauss, le doyen des chefs d'orchestre et le vétéran du bibelot.

Nous sommes décidément en force, et cependant nous serons certainement battus, car le bruit circule que de grands efforts ont été tentés pour empêcher le retour en France des merveilles qui vont passer sous le marteau. La presse anglaise a fait une campagne ardente, et des crédits extraordinaires ont été accordés par le Parlement à tous les musées de Londres.

Tous les objets d'art importés dans cette île sont condamnés à une réclusion perpétuelle. Il n'en est heureusement pas de même des artistes attirés à grands frais. Ils y perdent le goùt et l'esprit. Ils s'ennuient et s'en vont. 
La foule est compacte; on fait queue, surtout devant trois beaux meubles, reproduits ici par M. Giraldon, signés Riesner fecit, exécutés pour la reine MarieAntoinette, à l'apogée de l'art décoratif, sous le règne de Louis XVI : une commode, une table à écrire et un secrétaire couverts de bronzes splendides, dorés à l'or moulu, ciselés par ce grand artiste qui s'appelait Gouthière, et qui est en train de prendre place à côté de Benvenuto Cellini.

Le secrétaire, surmonté d'une petite galerie d'une légèreté exquise, porte la marque au feu du gardemeuble de la reine. Gouthière a mis tout son talent dans le médaillon du centre, dont les ors, éteints par le temps, s'harmonisent merveilleusement avec le ton général de la marqueterie.

La petite table à écrire est la plus haute expression de l'art et du style de cette époque. Riesner s'est surpassé; quant à Gouthière, ses ciselures valent leur pesant d'or.

Le dixième duc de Hamilton, grand-père de celui qui les vend aujourd'hui, avait payé ces trésors une dizaine de mille francs. Il était venu lui-même en France les acheter au petit Trianon, après 93 , à la Convention. L'aristocratie anglaise, à cette époque, avait voulu recueillir précieusement toutes les splendeurs de la famille déchue.

Il y a encore quelques beaux meubles dans cette exhibition: un splendide cabinet de Boule; une paire de vases de Sèvres gros bleu, avec une remarquable monture de festons de fleurs et de feuilles, un cabinet 


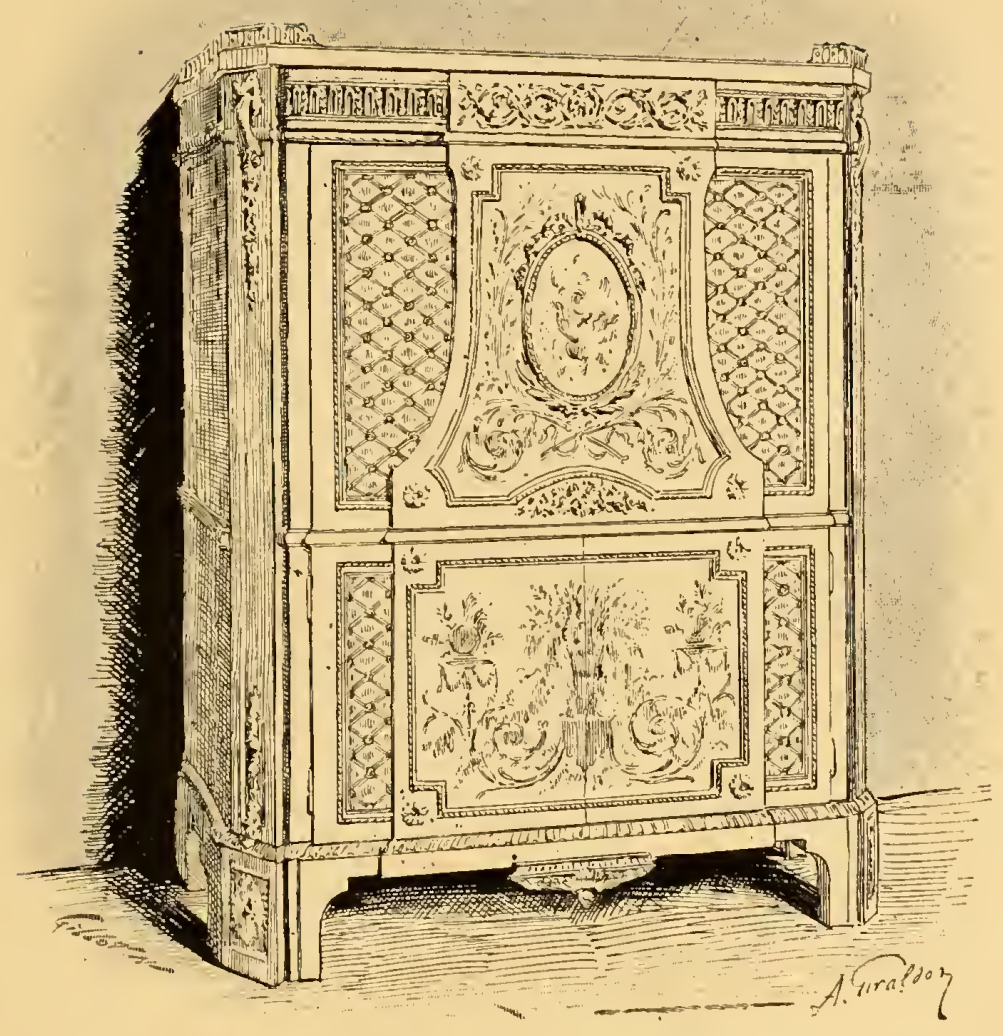

N" 3or, - Secrétaire de Riesner, avec ciselures de Gouthière (vendu I20 I20 fr.). $24,2+L^{-}$ 

de Florence enrichi de mosaïques en relief, un coffre en vieux laque noir parsemé de petits animaux faisant saillie, en or et en argent portant cette inscription: Formerly the property of Napoleon I.

Au milieu de l'éblouissement de toutes ces richesses, la foule s'arrête aussi devant le meuble de $\mathbf{M}^{\text {mo }} \mathrm{Du}$ Barry, signé par Pasquier; mais ce n'est là qu'une mystification. $\mathrm{NI}^{\text {me }}$ Du Barry avait certainement trop bon goût pour garder chez elle un secrétaire dont les panneaux sont recouverts de morceaux d'éventails reproduisant des pastorales assez faibles, et gardant encore la trace du pli des lames. Passons, c'est piteux.

Un mot maintenant rapide sur les toiles accrochées autour des salles, nous aurons tout le temps de les examiner et d'y revenir pendant l'adjudication.

Le Moulin d'Hobbema, un morceau capital, où le maitre, qui possédait un sentiment si profond de la nature, a exprimé d'une manière admirable la puissante vie végétale de la forêt, doit atteindre un prix fantastique. Ce tableau me paraît cependant bien audessous de celui qu'on admire au Louvre et qui fut adjugé 100000 francs à la vente Patureau. Dans celui du duc Hamilton, les vieux chênes au tronc rugueux, aux fortes branches, sont bien conservés, mais le moulin a été trop nettoyé. Il est usé, et c'est un grand défaut.

Voici des Téniers bien médiocres, des Holbein contestables, un Wynants signé et daté qui ne se distingue pas comme d'ordinaire par la finesse de ton, la légèreté de la touche et la précision du pinceau; et enfin 
un Rembrandt de pacotille, le portrait d'une horrible femelle qui dépare cette exhibition.

Arrêtons-nous cependant devant cet Ostade, un bouge enfumé avec ces buveurs trapus, communs, qu'on examine toujours avec un plaisir extrême, et devant ces fleurs de van Huysum. On pourrait les regarder à la loupe. Ces tableaux sont de la plus belle qualité. Le dernier nous a appartenu. Il était en 1793 dans la collection du duc de Praslin.

On a réservé comme bouquet de feu d'artifice, pour clore cette première journée, Daniel dans la fosse anx lions par Rubens, tableau célèbre qui a son histoire inscrite au livret. Il a figuré dans la collection de Charles $\mathrm{I}^{\mathrm{er}}$. Le catalogue porte, à son sujet, cette mention que je transcris fidèlement.

This is one of the fen great pictures by Rubens wich we know with certainty to have been entirely executea by his onn hand.

Textuellement : Ceci est une des rares grandes peintures de Rubens que nous connaissions avec certitude avoir été exécutée entièrement de sa propre main.)

Et il ajoute :

Rubens says this explicitly in an Italian letter to sir Dudley Carleton. (Rubens dit cela explicitement dans une lettre italienne à M. Dudley Carleton.)

Cette toile a sept pieds sur dix : neuf lions entourent le prophète qui, les mains jointes et le regard tourné vers le ciel, lui adresse une ardente prière. Il paraît peu rassuré, on ne sait trop pourquoi, car ses compagnons n'ont réeliement rien de féroce. Ils semblent au 


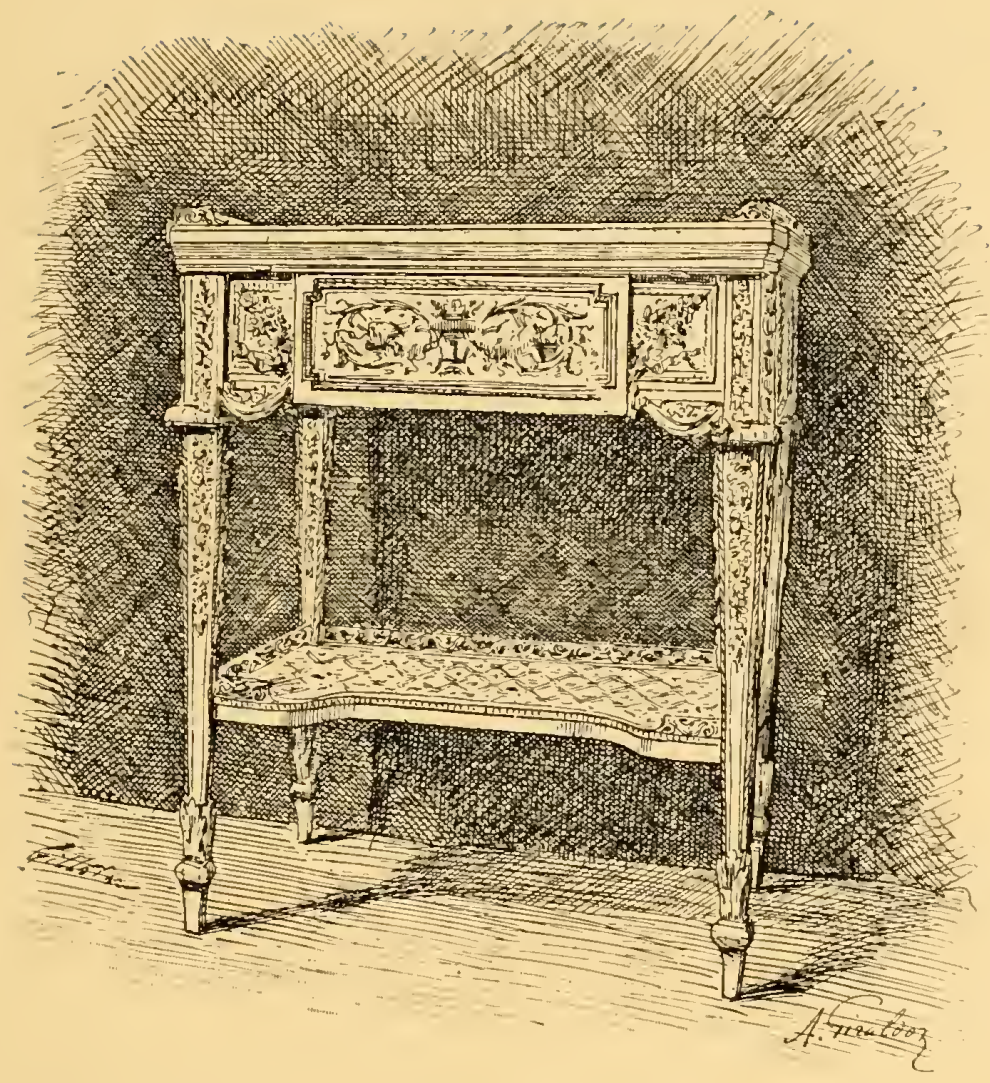

No 3o3. - Table à écrire de Riesner, avec ciselures de Gouthière (vendu $156000 \mathrm{fr}$. ). $3,2,5 . .2$ 

contraire heureux d'être ainsi distraits dans leur solitude par l'arrivée d'un nouveau venu.

Comme bien d'autres j'ai été fort peu séduit par ce tableau devant lequel s'arrêtent, pour discuter, les directeurs de toutes les grandes galeries d'Europe. Le peintre Ziegler a mieux interprété ce tragique épisode dans son tableau du musée de Nantes, qui est son chefd'œuvre. Danicl est debout, priant, le front en pleine lumière, tandis que les lions, domptés par son courage, lui lèchent humblement les pieds.

Vous le voyez, en somme, ce n'est pas une collection épurée comme celle de sir Richard Wallace ou comme les inestimables galeries du duc de Westminster. De belles choses à côté de fort médiocres. - Le public fera sans doute un triage intelligent.

Demain sera la grande bataille. 



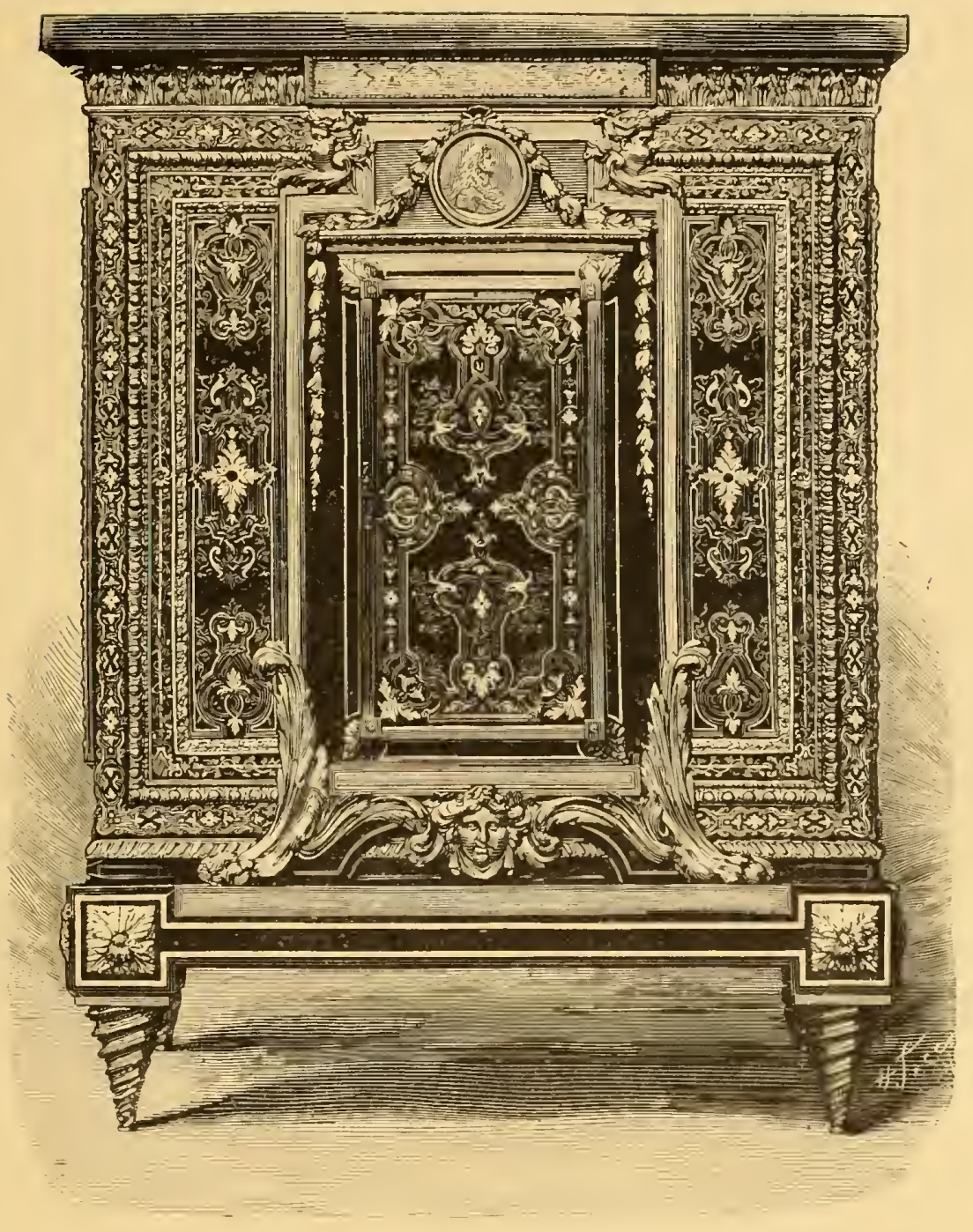

$\mathrm{N}^{\circ} 174$. Chifonnier Louis XIV (vendu 6o otio fr. 



\section{V}

Samedi 17 juin, premier jour de vente. Dès midi, la foule se dirige vers King street et se groupe devant l'hôtel Christie, qui ressemble à une gare au moment du départ d'un train de plaisir. Il s'agit d'entrer à tout prix et de conquérir une bonne place.

Une forte escouade de policemen, à l'habit bleu et au casque de feutre, maintient le bon ordre, mais elle a fort à faire. Il est difficile de contenir toutes ces impatiences curieuses.

Cette vente est décidément un grand événement à Londres.

Midi et demi. - On ouvre enfin. La porte subit un véritable siège : c'est un assaut en règle. On dirait d'une porte d'écluse brusquement levée. Le torrent se précipite dans l'escalier, cascade sur les marches, s'èlève jusqu'au premier étage et remplit la salle comme un bassin jusqu'aux bords.

La colonie française évite heureusement la bagarre. Grâce à l'obligeance de M. Gauchez et à la courtoisie des vendeurs, elle entre, un peu avant, par une porte dérobée, du côté de l'entrée des artistes, près de l'hôtel 
Dieudonné, et gagne des sièges réservés que les gardiens n'auraient pu défendre au moment de l'envahissement.

Nous sommes dans la place et des mieux partagés. Je regarde autour de moi.

Au premier rang, des chaises serrées les unes contre les autres représentent les fauteuils d'orchestre; viennent ensuite des banquettes, peu rembourrées peut-être, puis un simple gradin de bois qui court autour de la salle et permet aux spectateurs éloignés de se faire voir en se tenant debout.

Chacun est là sans distinction de noms et de qualités, pressé contre le voisin que le hasard lui a donné. Foule bigarrée, vieux blasons, lingots formidables, plumes célèbres, signatures puissantes, les plus grands noms et les plus petits, tous confondus pêle-mêle dans une promiscuité complète. C'est l'égalité absolue devant le roi bibelot.

Impossible de citer tous les assistants. Il faut cependant garder le souvenir de ceux qui assistent à la grande bataille. Indiquons donc d'après notre carnet :

Côté de l'aristocratie anglaise : le comte de Derby, lord Bingham, lord Torrington, la duchesse de Montrosc, lord Rosebery, lord Cork, duc de Somerset; sir Henri Baron, premier secrétaire de la légation britannique à Bruxelles.

Côté des musées : lord Powerscourt, président du conseil de la "National Gallery »; Burtor, son directeur; sir Leighton, président de la» Royal 


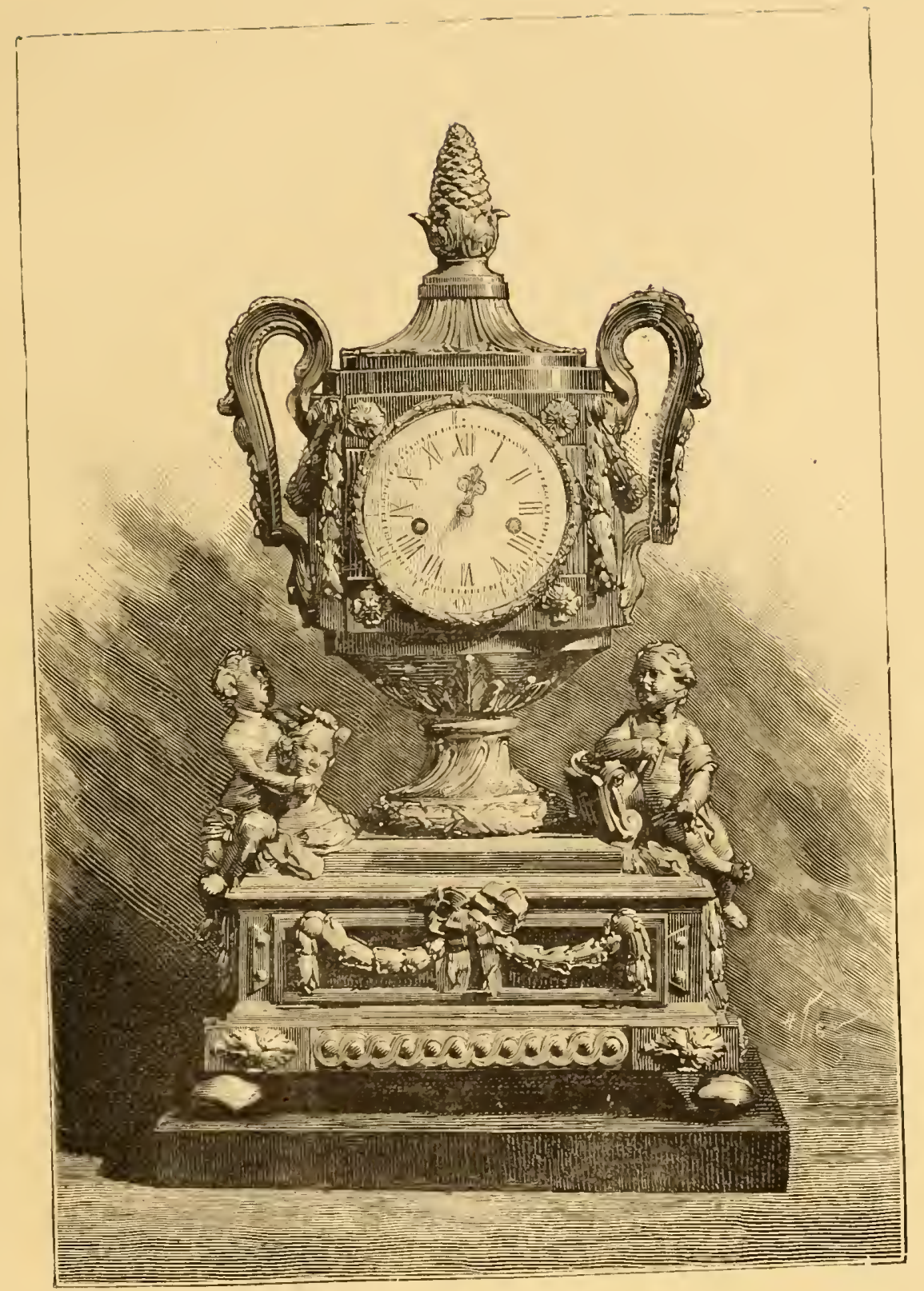

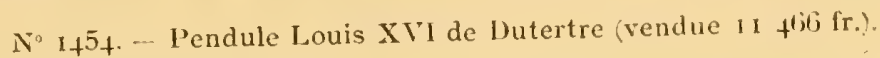



Academy "; Lippmann, du musée de Berlin; Courajod, du Louvre; Kohlbacher, du musée de Francfort; Doyle, directeur de la " National Gallery » en Irlande; Robinson, de la galerie royale de Windsor.

Côté des amateurs et des experts : Ferdinand Bischofsheim; Marius Hinsh, le rédacteur en chef de l'Art journal; White, représentant le duc de Westminster; Butter, John Lecomte, Beckett Denison; Chevallier, le successeur de Pillet; Charles Nannheim, le prince des experts; Leroy, de Bruxelles; Lacaze, chargé de la vente du Figaro; Gauchez, le propriétaire du journal l'Art de Paris, et le curieux, délégué de la Vie moderne, votre serviteur.

Côté des marchands, les noms les plus connus dans le commerce de la curiosité. Londres, représenté par Thibaudeau, Durlacher, Wertheimer, E. Joseph, Ch. Davis, Colnaghi, W. Agnew, le grand marchand de tableaux, membre du Parlement; - Paris, par Guénot, Stettiner, Nichel, Sichel, Sedelmeyer, Bing, Tripp et le jeune Seligmann; - Rome, par A. Castellani; - l'Allemagne, par Bourgeois, de Cologne;-Bruxelles, par Hollender.

Notez en outre les reporters des journaux, les curieux en bonne fortune de flàneric; les inconnus comptant profiter de l'imprévu; ceux qui aiment à suivre la marche rapide des livres et des guinées sur la raquette de l'enchère, ceux qui poussent toujours, mentalement disposés à corriger les injus- 
tices du hasard; ceux qui, comme Gabriel de SaintAubin, tiennent à étudier chaque acteur jouant son rôle, la vanité des uns, la cupidité des autres, la ruse de celui-ci et la méfiance de celui-là; - en tout, à peu près un millier de personnes et de personnages.

La salle est octogone, haute, spacieuse, bien aérée, ce qui est fort agréable, et, ce qui ne l'est pas moins, bien éclairée par une large coupole. $\mathrm{Au}$ milieu pendent des lustres en cristal de roche et en bronze doré, que l'on doit vendre et qui, en attendant leur sort, servent à l'ornementation générale.

Les murs sont garnis, de haut en bas, de grandes traverses en bois destinées, pendant les expositions, à accrocher les tableaux. Dans le fond, une claire-voie, à hauteur d'homme, forme la rampe et sépare le public des premiers rôles chargés de la vente. Ce sont là, les coulisses et la scène. La consigne est sévère. Personne n'y peut pénétrer, à part les acteurs, qui sont les auctioneers, et les figurants, représentés par les hommes de service.

La tribune du commissaire-priseur se trouve à l'extrémité d'un bec prononcé, sorte de $\mathrm{V}$ que forme la balustrade, et qui avance au milieu du public. C'est une chaire portative en bois verni, comme celles de certaines églises. Moins les roues, sa forme ressemble aux chars des quadriges romains de l'Hippodrome. L'auctioneer conduit la vente au lieu de mener les chevaux, voilà tout. Détail important : les ama- 
teurs, groupés sur des gradins en amphithéâtre, ne se tiennent pas derrière lui, envahissant son sanctuaire, ainsi qu'à Paris. - Prenez des notes, maître Chevallier! à notre retour sur le continent, nous serons tous pour le confortable des aménagements anglais. Ils adouciront agréablement le sort des patients de l'hôtel Drouot. 



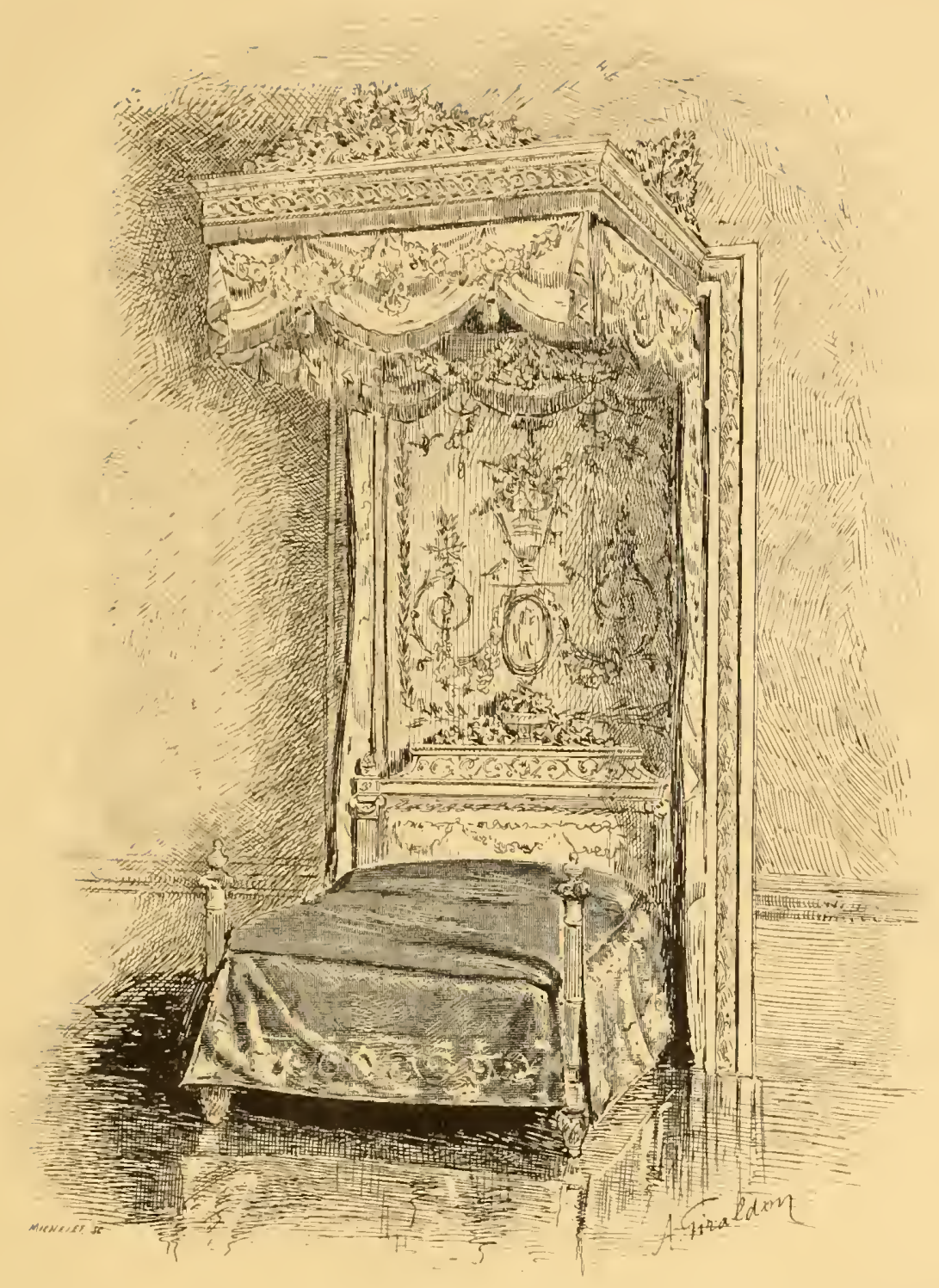

No1912. - Lit Louis XVI, tapısserie des Gobelins (vendus $30030 \mathrm{fr}$. 



\section{I}

Un peu avant une heure - cela se passe ainsi dans tous les pays - une certaine impatience se manifeste dans le public. Il pétitionne déjà des pieds, des mains et de la canne pour faire commencer bientôt la petite fête.

M. Thomas H. Woods doit présider la séance. Il est le dernier arrivé dans cette vieille maison Christie, fondée au commencement du siècle, et qui paraît vouloir se perpétuer de génération en génération, en ajoutant, de temps à autre, le nom d'un nouvel associé à sa raison sociale. Ils sont trois maintenant; à la fin du siècle, ils seront quatre.

Une heure précise. - Un grand silence se fait : M. Woods monte à la tribune. On n'est pas plus exact. C'est un homme de cinquante ans environ, dont la physionomic a quelque ressemblance avec Delaunay, de la Comédie-Française. Sa taille est moyenne, ses yeux fins, ses lèvres minces, ses cheveux gris. Ses joues encadrées de légers favoris sont roses, et animées peut-être par le brandy de la dernière heure. L'expression paraît un peu railleuse. Comme tous les Anglais, il porte une fleur à sa boutonnière. 
Avant l'entrée en matière, il sent le besoin, en raison de l'importance de la vente, d'adresser à son auditoire un petit speech bien senti, et s'exprime à peu près en ces termes :

"Gentlemen, ladies, la collection qui va être bientôt dispersée présente un intérêt sans précédent. Vous connaissez ses origines. Elle a été formée par deux hommes de goût : M. Beckford et le duc Alexandre de Hamilton. Plus heureux que vous ne le serez sans doute, ils ont acheté ces trésors à une époque où ils étaient moins recherchés que maintenant. Grâce à leurs soins, ils ont su les garder dans l'état remarquable de conservation où ils se trouvent aujourd'hui.

"J'ai souvent entendu dire, depuis quelque temps, autour de moi, que la plupart de ces beaux ouvrages devaient prendre place dans la "National Gallery », je le désire sincèrement, en ce qui me concerne, car je suis de ceux qui pensent que tous les objets d'art importés en Angleterre ne doivent plus en sortir. Nous sommes assez riches pour les défendre. »

"Bravo! bravo!" crie la foule en applaudissant ces paroles patriotiques.

Immédiatement après commence la vente. Elle suit l'ordre des numéros du catalogue dressé en conséquence, ce qui est un bien grand avantage dont on devrait nous gratifier à Paris. - A inscrire sur le cahier des doléances des habitués de l'hôtel Drouot, et à renvoyer à l'examen, à l'étude et aux méditations de mon ami Charles Mannheim.

M. Woods ressemble à un général placé sur une 
éminence, et commandant le feu avec calme. Armé de son hammer (marteau), semblable à un bouton de porte en ivoire, il n'indique aucune valeur, laisse partir les offres de très bas, répète les enchères qui se succèdent avec rapidité, et dès qu'il se produi un temps d'arrêt, adjuge en donnant un coup sec, et en inscrivant lui-même l'achat. S'il y a une réclamation quelconque, il recommence de suite la mise en vente pour éviter un conflit. Tout se passe, du reste, avec une précision et une régularité parfaites ne laissant rien à désirer.

Derrière lui, plus bas, presque dissimulé, faisant au besoin l'office de souffleur, se tient l'un de ses collaborateurs, M. Christie, - moustache blonde, favoris courts, l'œil doux, sympathique - et avec cela quelque chose rappelant le duc d'Aumale lorsqu'il était plus jeune. Il aide, sans en avoir l'air, son associé dans sa tâche, surveille les enchères passant inaperçues, et se tient prêt à lui transmettre les communications importantes qui peuvent survenir.

Le service se fait avec aisance, mais la maison, avouons-le, ne semble pas s'être mise en grands frais de livrées pour ses waiters (domestiques). Bien qu'ils portent tous des cols cassés, leur tenue est des plus négligées. Ils ont l'air d'infirmiers avec leur veston gris sous lequel paraît un tablier blanc de valet de chambre, et leur petite calotte sur la tête leur donne l'air des cavaliers à l'heure matinale du pansage des chevaux.

Ces commissionnaires préparent dans la coulisse ce qui doit suivre ce que l'on vend. Il n'y a pas ainsi un 
instant de perdu. Tous les numéros se succèdent rapidement; aussi fait-on, en moins de temps et sans bruit, plus de besogne que chez nous.

Le tableau à vendre ne circule pas comme ì l'hôtel Drouot, porté en triomphe par des hommes maladroits qui l'éclairent mal, quand ils ne vous montrent pas l'envers de la toile, au lieu du côté de la peinture. A Londres, il est placé sur un pupitre un peu haut, qui tourne comme un lutrin, suivant l'impulsion donnée. Il est mis ainsi à la portée de tous les regards, en bonne lumière, avec une inclinaison étudiée. Tout le monde voyant bien, personne ne s'approche avec une loupe et ne demande à revoir.

Et la vente va ainsi au milieu du plus profond silence. Pas un mot. On enchérit d'un geste. L'enchère se poursuit rapide, serrée, répétée d'un ton monotone par l'auctioneer au flegme britannique. Il commence par les shillings, puis les livres sterlings A cent livres, il ne prend plus que des guinées.

"Twenty guineas! Five! - Thirly guineas! Five! - Fourty! Five! - Fifty! Five! - Sixty guineas! Five! - Seventy Five!" Et ainsi de suite, comme le tic-tac d'un battant de pendule.

De temps en temps cependant, sortant de ses habitudes et des traditions de la maison de King-street, MI. Woods se permet quelques réflexions autorisées par les circonstances. On ne vend pas tous les jours des collections comme celles du duc Hamilton! Tantôt il fait ressortir le mérite de l'œuvre, tantôt il en décrit I'historique. Quelquefois, avec un bon goût parfait, il 
convient des erreurs du catalogue. D'autres fois il stimule et enlève ainsi son public :

"Plus vite! plus vite! si vous voulez atteindre rapidement la valeur de cette toile. Vous venez de payer un tableau ordinaire très cher, et vous hésitez maintenant pour un chef-d'cuvre!"

Il se permet même quelques railleries en présentant une croûte :

"Pour ce splendide Paul Potter, voyons, donnerat-on quinze guinées? Je cherche vainement dans la salle le monsieur qui est venu me dire ce matin qu'il le pousserait beaucoup plus haut. "

Après avoir adjugé un tableau, il lui arrive de lancer une épigramme contre l'acquéreur :

"Il est fàcheux que ce tableau aille dans une galerie particulière fermée au public. On ne le verra plus. Il est condamné à une réclusion perpétuelle. "

Cela tombe sur un grand seigneur. Tant pis pour lui s'il n'est pas satisfait. La maison Christie, Manson et Woods est aujourd'hui une puissance. Tous les amateurs ont besoin d'elle; elle n'a besoin de personne. 



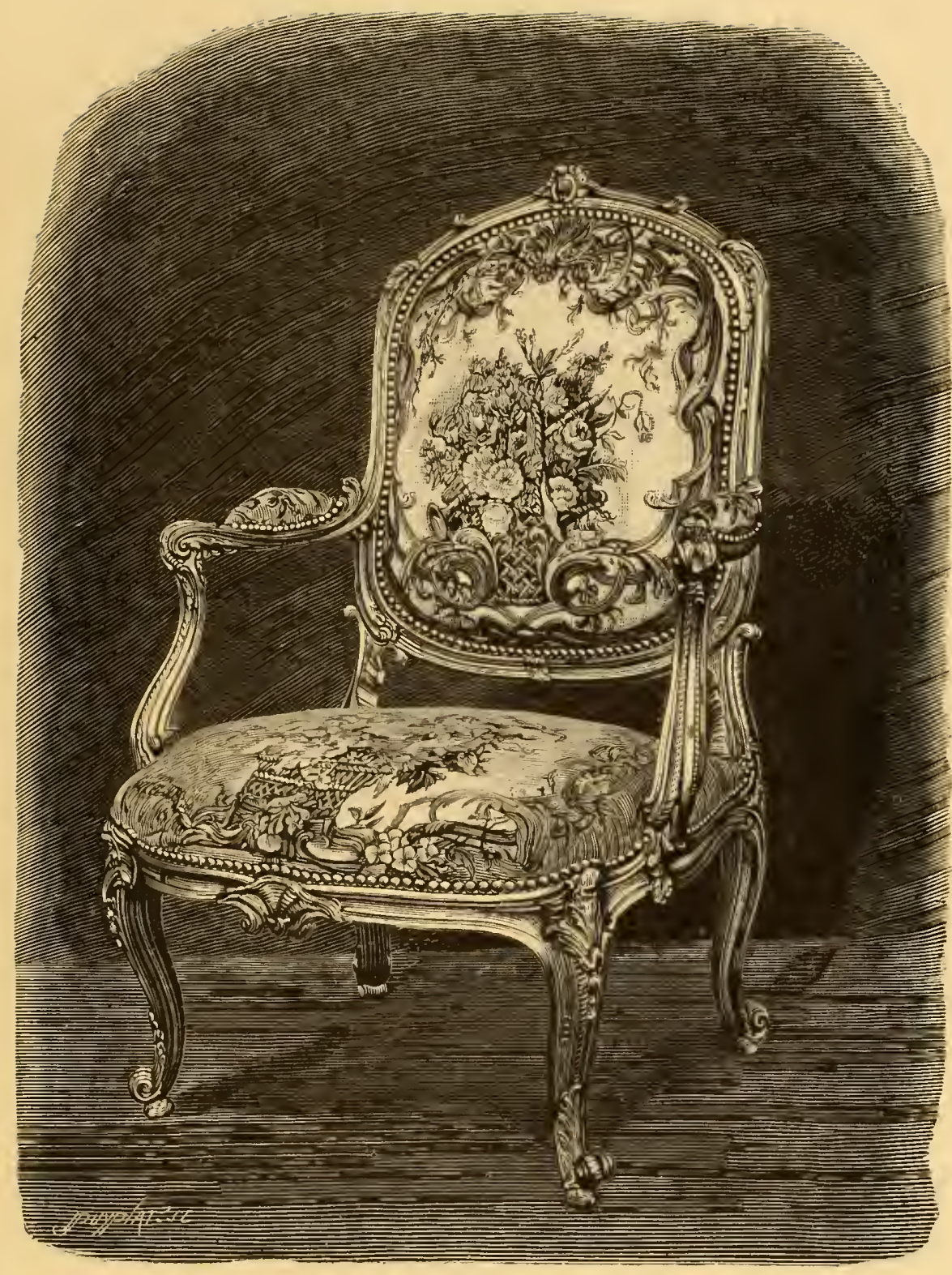

No 1905 . - Fauteuil Louis XVI, Gobelins (les douze vendus 23 I 72 fr.) $\quad-\quad-t$ 



\section{I I}

Mes aimables lecteurs n'attendent certainement pas de moi la longue nomenclature des tableaux, avec la liste des prix obtenus. Un chiffre ne dit rien d'ailleurs. Il faut voir la chose ou la décrire avee soin. Le catalogue déjà est un gros volume de i 200 numéros; pour mentionner tout, il serait nécessaire d'écrire un livre. Le temps et la place me manquent pour cette besogne, dont je laisse la charge à la presse quotidienne. Pour cette publication, je me bornerai à passer très rapidement la revue des principaux objets.

La première journée est consacrée aux peintres allemands et flamands. Je ne parlerai que de quelques-uns.

Pour le Moulin à eau d'Hobbema, dont il a déjà été question, on arrive vite à 3000 guinées, puis rapidement à 3500, et par enchères de roo guinées à 4000 . M. Sedelmeyer, de Paris, en mettant par 50 guinées: couvre la dernière enchère à 4250 guinées (à 27 francs, 109350 francs).

"Jamais on n'a vu un plus bel Hobbema dans cette salle ", avait dit M. Woods, pour stimuler son public.

Un Portrait d'homme d'Holbein, 5670 francs. 
Qui done aurait des Holbein, si l'Angleterre n'en avait pas! Durant un quart de siècle, il est toute la peinture en Angleterre. Il y en a partout, à Hamptoncourt, à Kensington, à la National Gallery, dans toutes les résidences royales et dans tous les châteaux de la vieille aristocratie. Il y en avait trois encore à la vente Hamilton, mais nous ne parlerons pas des autres.

Le Portrait d'Albert Durer par lui-même, signé du monogramme et daté de i507. Le maître est représenté avec un vêtement noir, enveloppé d'un grand manteau brun. Un sablier est près de lui; traduction libre: Time is money. Allusion délicate, de nature à flatter les Anglais.

Ce tableau paraît très discuté. D'aucuns n'y reconnaissent pas l'exécution large, facile, avec ces contours ciselés qui rappellent la main ferme du graveur. Le docteur Waagen, directeur du musée de Berlin, affirme (Treasures of Art in Great Britain, I 854), que c'est une ancienne copie. Si je ne me trompe, le musée de Lyon a un superbe portrait d'Albert Durer, où le maître est représenté avec ses longs cheveux d'or. Il faudrait pouvoir le comparer pour se prononcer.

En présence de ces contestations, M. Woods contourne la difficulté, et déclare qu'il s'agit d'une replica, seconde édition de l'original, de grandeur naturelle, au musée de Madrid.

M. J. H. Pollen achète ce tableau ro 635 francs.

Passons maintenant à la collection des portraits historiques, et à tout seigneur tout honneur. Commen- 
çons d'abord par Van Dyck, cet inimitable artiste qui peignait plutôt avec la volonté qu'avec la main. Arrêtons-nous! le catalogue mentionne quatre tableaux de lui :

Henriette de Lorraine, splendide portrait signé et daté de 1634 , qui figurait dans la collection de Charles $I^{e r}$, et plus tard dans la galerie du duc d'Orléans. Bien belle la princesse de Phalsbourg, sœur du duc de Lorraine, dans sa robe de soie noire drapée sur une jupe de satin blanc, la relevant d'une main par un mouvement gracieux, tandis que de l'autre elle s'appuie sur l'épaule d'un petit nègre habillé en page rouge, et portant, sur un plateau d'argent, un monceau de roses épanouies.

L'auctioneer ne peut s'empêcher de dire, avec raison, qu'aucun de nos artistes parmi les plus célèbres ne pourrait se charger de faire un chef-d'œuvre pareil.

Acheté 2000 guinées (5400o francs), par M. Ch. Davis fils qui, de notoriété publique, opérait pour le compte de lord Rosebery.

De Van Dick encore, la Duchesse de Richmond, en robe de soie blanche, à l'âge de vingt ans, dans tout de l'éclat la jeunesse. A côté d'elle, son fils, armé d'une flèche, un Cupidon de quatre ans. Tout un poème!

Bien inspiré, MI. Beckett Denison, une des grosses fortunes de Londres, se paye ce portrait étincelant de lumière pour la modeste somme de 53222 francs.

De lui toujours, Charles I, habillé de blane et de rouge, avec le ruban de l'ordre de la Jarretière. 21000 francs, pour M. Sedelmeyer. La comtesse de 
Verrue possédait, elle aussi, un superbe Charles I ${ }^{\text {er }}$ qui est au Louvre.

De lui enfin, le portrait de la Reine Henriette-Marie, acheté 700 guinées par MM. Agnew et fils.

Voici maintenant Rubens, ce travailleur infatigable, à la couleur onctueuse, grasse, fine et lumineuse, qui a couvert de son pinceau plus de deux mille toiles dans sa carrière. Ni Murillo, ni Titien, n'en ont jamais produit autant.

Il est largement représenté dans la galerie Hamilton.

Le Duc d'Olivarēi, entouré d'anges et d'ornements symboliques dans un ovale en grisaille. I.e comte-duc eut l'honneur d'être également peint par Van Dyck. A M. Winckworth, pour 12150 francs.

Portrait à trente ans, en 1662, de Elisabeth Brandt, sa première femme. Vêtue de belle soie, couverte de bijoux au corsage et de bagues aux doigts - la coquette! Nous connaissons tous cette belle et saine créature, grasse et potelée, peinte souvent par le maître, sans mystère pour personne, des pieds à la tête. Déshabillée bien des fois en divinité mythologique, elle lui servit de modèle dans son tableau des Trois Grâces.

Peinture franche et expressive, achetée 47760 francs par T.-M. Whitehead pour le duc de Westminster, dit-on.

La Naissance de V'énus. Un modèle de plat d'argent exécuté en grisaille, probablement pour Charles Ier. Le maître est là, toujours admirable dans ses petits tableaux bien plus encore peut-être que dans ses grandes peintures décoratives. 
M. Gauchez le sait bien, aussi il lutte avec acharnement contre MI. Beckett-Denison, mais la victoire reste à ce dernier, à 4368 o francs.

Terminons les Rubens par les Amours des Centanres. La scène, un peu voluptueuse, se passe dans un paysage d'Arcadie d'une grande énergie de touche.

De 500 guinées, les enchères marchent à pas de géant à 1500 , et le tableau est enfin adjugé pour 2000 guinées (5, ooo francs) ì MI. Stewart. Mais tout le monde sait qu'il s'agit là d'un nom de guerre.

Voyez la marche des prix de la peinture : achetée 260 guinées en 1802 , dans une collection particulière, cette toile fut vendue en $18 \mathrm{ro}$, dans la collection C. F. Greville, à M. Christie pour 610 guinées.

Viennent ensuite le Cabaret, de Van Ustade, 1750 guinées, par M. Beckett Denison; un Paysage, de Jacob Ruysdael, I 60 guinées, à Martin Colnaghi.

On enlève enfin les voiles qui cachent le Daniel dans la fosse aux lions, de Rubens, autour duquel il s'est fait tant de bruit à l'exposition.

Profonde sensation, comme à la Chambre. Dans un choc électrique, la salle entière bat des mains avec frénésie. Il faut quelques minutes pour remettre au repos ces âmes surexcitées.

Magnificent picture! me dit mon voisin émerveillé. - Je hausse imperceptiblement les épaules.

M. Woods déclare d'abord qu'il espère bien voir entrer ce chef-d'œuvre dans la " National Gallery». - En Angleterre, c'est le cliché ordinaire pour 
recommander un tableau. En France, c'est le Louvre qui est mis en cause.

Il rappelle, en outre, que précédemment plusieurs amateurs s'étaient cotisés pour offrir au pays certains tableaux du premier ordre, tels que la Sainte Famille, de Josuah Reynolds, et le Champ de blé, de Constable, si admirés aujourd'hui dans les galeries de l'État. Il ajoute, qu'animés de la même intention, plusieurs gentlemen ont voulu se faire inscrire chez lui, mais il a dû suspendre cet élan.

"Le sentiment national, dit-il en terminant, prévaudra contre les tentatives des étrangers pour enlever ce trésor à l'Angleterre! »

Quelle réclame! Elle ne serait certainement pas tolérée chez nous. Le commissaire-priseur qui agirait ainsi serait certainement bien vite rappelé à l'ordre par les assistants.

Malheureusement, il y a quelques jours, le bruit s'est répandu, par quelques érudits, que depuis soixante ans, il existe un autre Daniel absolument semblable, comme sujet et comme dimensions, à l'église de Goldshill, près de Ryde, dans l'île de Wight, et que ce tableau, autrefois dans la collection de sir Richard Worsley, à Appuldurcombe, fut offert plus tard à la paroisse par le conte de Iarborough, marié avec sa nièce et héritière.

Décidément est-ce l'original, une répétition, ou une copie? That is the question. Ce qu'il $\mathrm{y}$ a de bien certain, c'est que Rubens vendit "6oo florins un Daniel au milieu d'un grand nombre de lions fait 
d'après nature, 12 pieds sur $\delta$, original entièrement tait de ma main ", et que ce tableau se trouve ainsi textuellement décrit dans la liste delli quadri che si retrolono in casa mia, qu'il envoya d'Anvers, lc 28 avril 16 I 8 , à sir Dudley Carleton, ambassadeur du roi de la Grande-Bretagne à la Haye. - J'ai vérific moi-même sur d'anciens documents cette assertion du catalogue. Elle est exacte.

Quoi qu'il en soit, cette découverte, encore mal établie, jette un froid. On part cependant de rooo guinées. Ce prix est immédiatement couvert, on met 2000. Par 500 guinées, on arrive à 4000 assez vite. Puis, un peu plus lentement, aree des temps et par 100 guinées, on marche jusqu'à 4800 guinées. Arrivé lì, M. Burton, le directeur de la "National Gallery » hésite un moment. Le prix est élevé! M. Beclett Denison, qui paraît vouloir à tout prix se former un musće, en profite. Il met une dernière enchère, et à 133770 francs le Daniel lui est adjugé au milieu d'applaudissements multipliés.

Depuis, le vicaire de Goldshill, M. Ratcliffe, un habile homme, qui s'était tu jusque-là, par tactique sans doute, a adressé à l'éditeur du Times une longue lettre pleine de renseignements sur le sosie de la vente Hamilton. Subsidiairement, il a cru devoir ajouter que le tableau n'étant pas à une place où il pût être sérieusement apprécié, l'Église avait décidé de s'en séparer, s'il convenait à M. Burton de joindre cette belle cuvre aux merveilles du Musée National, ou bien encore sielle était désirée par quelque 
amateur désolé de n'avoir pu acquérir celle du palais Hamilton.

Pas maladroite cette petite réclame! non payée sans doute et venant bien à son tour et à sa place. Mais, maintenant que deux Daniel sont bien constatés, il y aura baisse sur les deux. C'est inévitable. Du reste, soyez-en bien convaincus, les ventes ont leurs entraînements et leurs satisfactions d'amour-propre. Les hommes sont ainsi faits : un achat à l'île de Wight, en dehors de la fièvre de King-street, ne tentera plus personne, et le Daniel numéro deux restera encore longtemps, avec ses lions où il se trouve. 


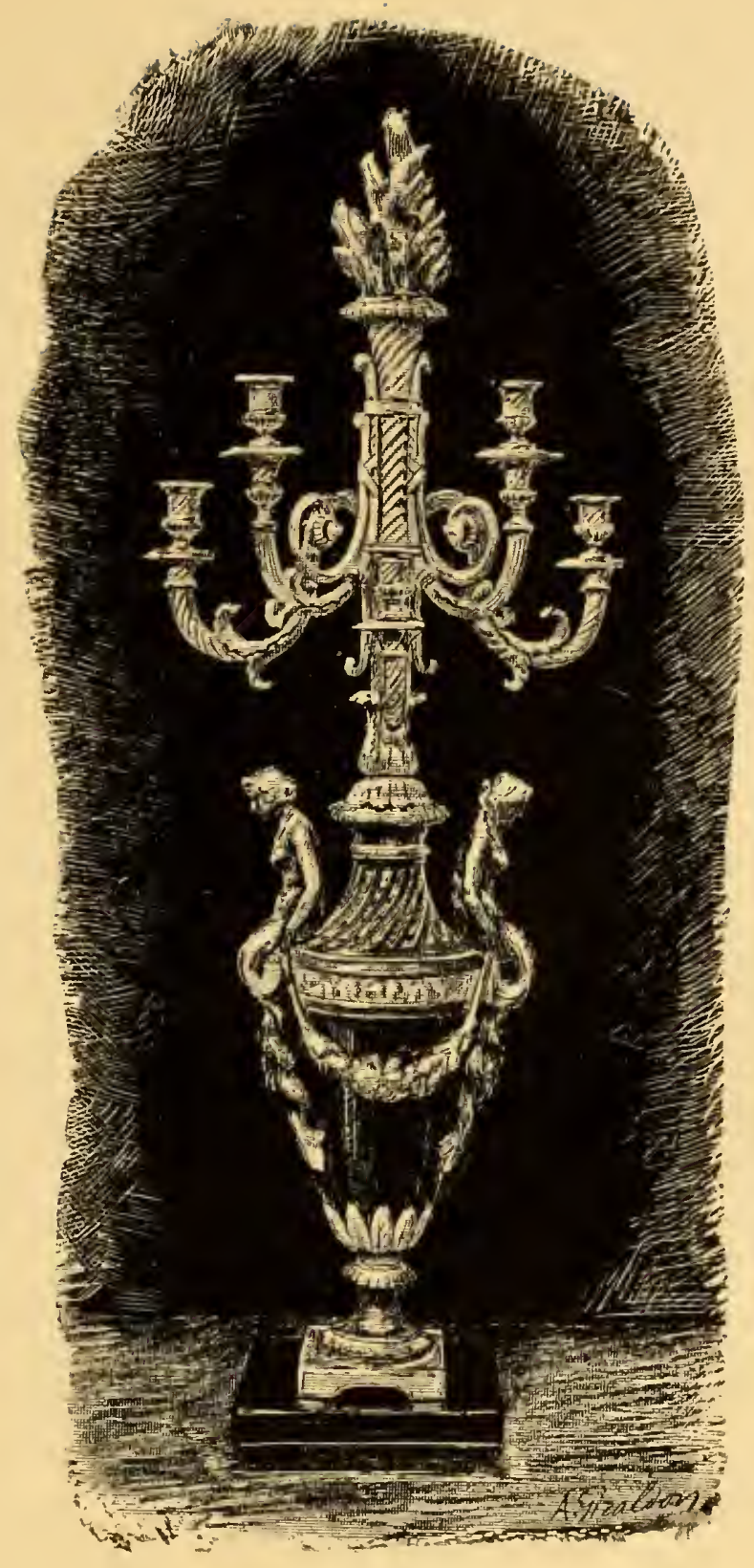

No 658. - Candélabres Louis XVI (une paire vendue 6 r 4 lo fr. et une autre semblable $72332 \mathrm{fr}$.). 



\section{VIII}

Le lendemain, second acte de cette féerie artistique en trente-quatre tableaux. Changement de décor. Les meubles sont dans le fond de la salle et bien en vue. Au milieu de la salle, une grande table en fer à cheval, couverte d'un tapis vert autour duquel se groupent les principaux acheteurs. Derrière eux, deux rangs de banquettes. Dans le fond se tiennent, comme ils peuvent, les retardataires. L'auditoire agité de la veille est redevenu calme. Le public paraît très distingué. Rien de la brocante de l'hôtel Drouot. Les premiers rôles seulement de la curiosité. La colonie française est aux premiers rangs : MMI. Cernuschi,Barre, Sichel, Guénot, Bing, John Lecomte, Mannheim et autres.

Les waiters vont, viennent à leur aise, protégés par la grande table fermée contre l'envahissement du public, qui ne peut ainsi pénétrer dans les coulisses. Pas de commissionnaires comme à Paris, jouant du coude et faisant une trouée au milieu des amateurs pour arriver au "magasin", toujours bondé dans les grandes ventes, ainsi qu'un navire prêt à couler bas.

MI. Christie vend cette fois. Il a pris le marteau, un scribe à ses côtés. Il ne sollicite pas le public comme 
son associé. Au contraire il opère, suivant les vieilles traditions, avec une grande impassibilité, au milieu d'un grand silence. Il a soin de n'annoncer ni un défaut, ni une fêlure, ni une restauration. Vous avcz $\mathrm{vu}$, cela suffit.

C'est la journée du Japon, avec ses grands plats tatoués d'azur, et de la Chine, avec ses céladons craquelés.

D'abord défilent les assiettes. Elles se vendent un prix exorbitant, au moins trois fois plus cher qu'a Paris.

Une paire de vases en vieux mandarin avec un décor de fleurs sur fond gris et rose est adjugée pour rien : -32214 francs!

Deux bouteilles de jade indien, à la forme ventrue, à l'ornementation de fleurs et de feuillages en lapislazuli et montées en or sous Louis XVI. :- 3957 francs.

Un cabinet de Boule, 60 o6o francs, et une commode d'ébène aux armes de France et au chiffre du comte d'Artois, 19916 francs. - Deux tables de porphyre d'Égypte, un prix fantastique : 49140 francs.

Nous arriverons tout de suite à la troisième vacation où passent en vente les trois meubles de Riesner, les célèbres $\mathrm{n}^{\circ \mathrm{s}} 30 \mathrm{I}, 302$ et 303 , qui représentent si bien ce goût français sans rival dans le monde entier, à l'époque où, la Révolution grondant déjà sourdement à l'horizon, Marie-Antoinette jouait à la fermière, à Trianon, avec le comte de Provence comme bailli et le comte d'Artois comme fermier.

C'est avec un accompagnement d'applaudissements 


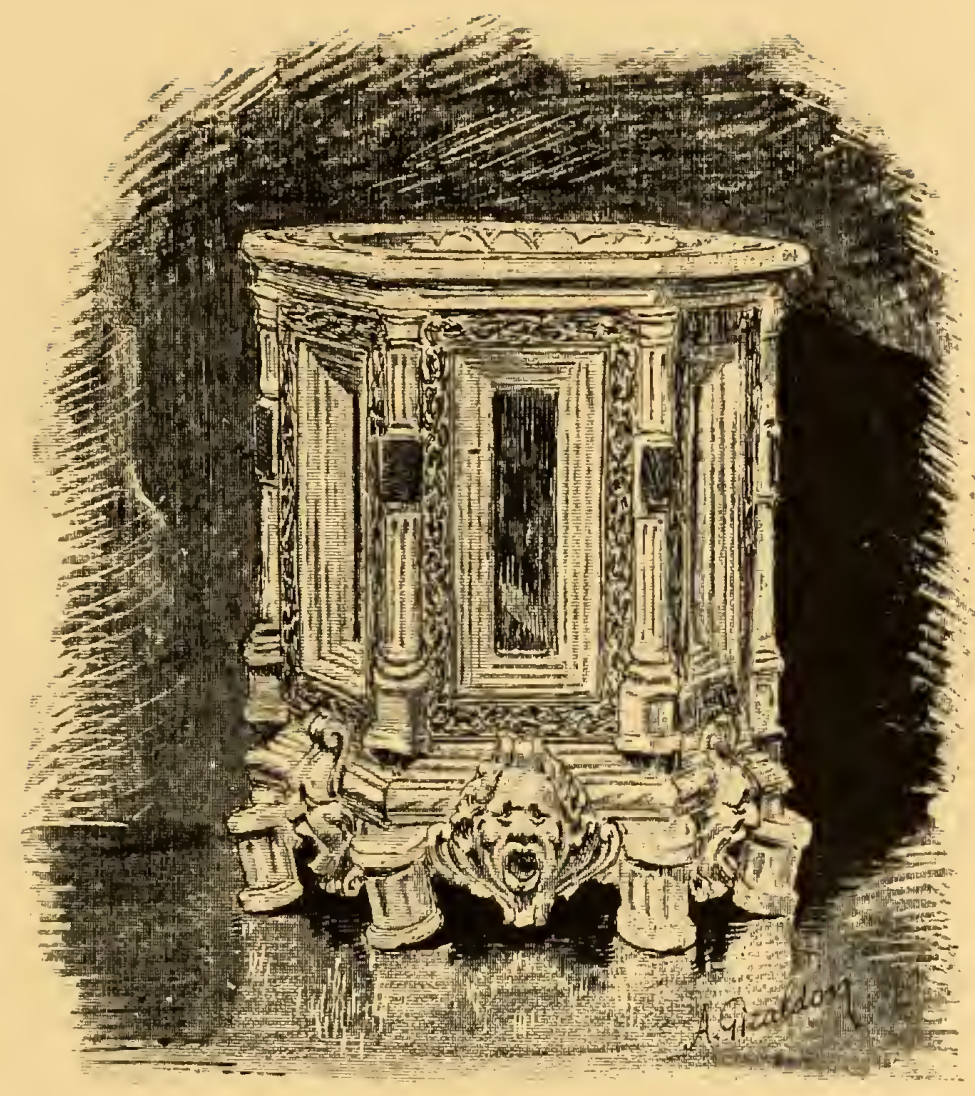

$N^{\circ}$ 960. - Salière en faïence d'Oiron (vendue 22 ooo fr.). 

redoublés que se fait cette adjudication. Nous nous sentons tous fiers devant cet hommage rendu à l'art français. Il nous semble que ces bravos sont pour nous. Un peu plus nous saluerions.

La petite table à écrire, meuble délicat et exquis, exposé en 1862 au musée de Kensington, ouvre la marche, suivant l'ordre du catalogue. Ce sont d'abord des escarmouches légères, des combats d'avant-garde.

Mise à prix à 3000 guinées, elle monte à 4000 et arrive à 4500 du premier coup. Là les enchères se calment. L'auctioneer ne les cueille plus que par cent guinées. A 5500 livres sterling, un temps. La lutte se circonscrit entre Londres et Paris. D'un côté M. Stettiner tient notre drapeau national, de l'autre M. Wertheimer, le riche marchand de Bondstreet soutient le chac, au nom de l'Angleterre. Le combat devient peu à peu très vif. Sur les confins de 5700 la chose devient sérieuse et le silence redouble. A 59oo, M. Stettiner s'arrête : il paraît désespéré. M. Christie interroge alors une dernière fois du regard MI. Wertheimer. Il se décide à faire un signe -6000 livres sterling! C'est à lui! Plus de 150000 francs l'ceuvre de Gouthière!

M. W. Boore (toujours la Grande-Bretagne) achète ensuite le secrétaire de $\mathrm{I} 79^{\circ}$, portant le chiffre de la reine. La lutte est courte. De 1500 on arrive presque d'un scul bond à 4400 guinées, - (11880o francs !)

La commode part de 1000 guinées pour atteindre 4090 guinées. A 100430 francs, elle passe entre les mains de M. Stettiner qui prend enfin sa revanche. 
Cette fois c'est pour la France. Nous allons rentrer dans notre bien, mais la restitution est coûteuse.

Total, les trois meubles : 385230 francs! Ce n'est pas cher.

Elles valaient bien un demi-million ces précieuses reliques! qui du Trianon étaient allées au palais Hamilton.

Ces trois amis n'avaient jamais été séparés, ils vont se quitter pour toujours. L'un va chez le duc de Westminster, chez les Rothschild se rendent les autres, dit-on. Sunt lacryma rerum! "Les adieux seront touchants ", a dit un spirituel écrivain de mes amis. 


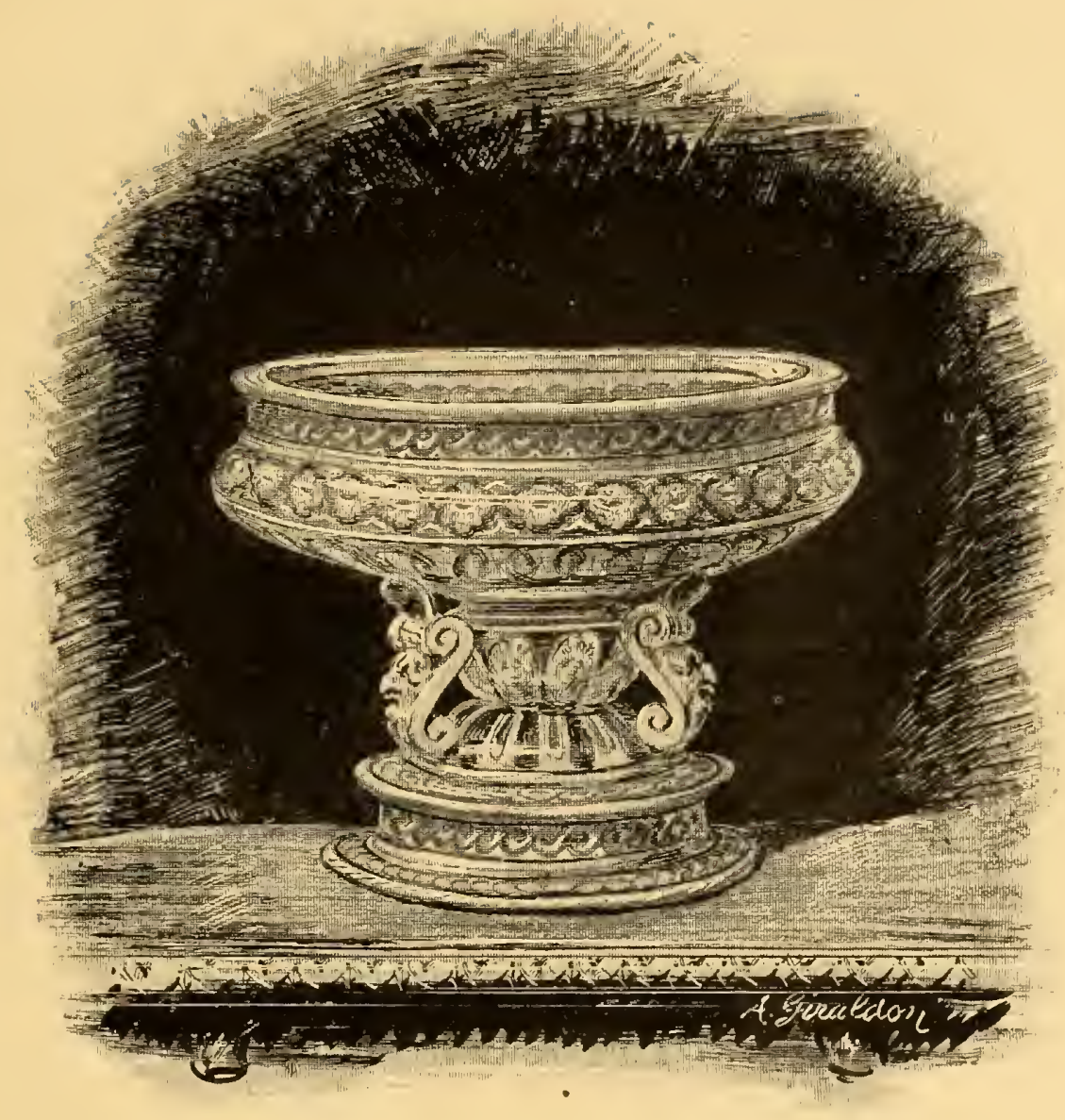

$N^{\circ} 9^{61}$. - Coupe en faïence d'Oiron (vendue 30668 fr.) 



\section{IX}

La vente continue ainsi trois fois par semaine, mémorable bataille de l'art contre l'argent. L'or ruisselle, les lingots se fondent, les bank-notes volent en l'air comme des nuées de papillons. La foule reste houleuse jusqu'au bout, se précipitant dès l'ouverture dans les salles de vente ou dans celles d'exposition du premier étage. Les journaux de Londres, le Daily Nen's et le Times en tête, enregistrent chaque jour de longs récits des enchères. Ce duel entre la France et l'Angleterre est palpitant, mais, nous l'avons déjà dit, il est impossible de passer tout en revue. Il faut forcément, en ce qui me concerne, abréger mon récit; car en ne consacrant que trois ou quatre lignes à chaque article, il serait nécessaire d'écrire un in-quarto pour aller jusqu'au bout. Je dirai seulement quelques mots maintenant des tableaux, surtout de ceux de l'École italienne puis je passerais rapidement en revue les principaux objets d'art français. Ce sera un inventaire très sommaire, et ma tâche sera ainsi finie.

L'Histoire de Myrrha de Giorgione baptisée Hippocrène et Atalante par le docteur Waagen, qui se 
trompe souvent, est adjugée seulement 3684 o francs au Musée national, représenté par M. Burton, accompagné de deux mandataires munis de pleins pouroirs, MM. Howard et Gregory. -- Consolons-nous, le Louvre a un chef-d'ceuvre de Giorgione: le Concert champêtre, de la collection de Charles $\mathrm{I}^{\mathrm{er}}$.

Encore plus rare! -- L'Assomption de la Vierge de Sandro Botticelli, le meilleur élève de Filippo Lippi est une des bonnes toiles de la vente. Vasari a raconté que ce chef-d'œurre avait été peint pour l'église de Saint-Pierre Majeur de Florence, sur le plan donné à Botticelli par Matteo Palmieri. Au bas, les apôtres entourent le tombeau de la Vierge arec le donateur et sa femme. Au-dessus, le couronnement de la mère du Christ. Au sommet, assistant à cette fête, trois cercles de trois rangées de figures d'une extrême élégance, fines comme des miniatures de missel : patriarches, prophètes, apôtres, évangélistes, martyrs, empereurs, docteurs, vierges à la beauté idéale er aux formes séraphiques; en un mot, toute la hiérarchie céleste. Tous tiennent un bâton doré à la main. Au fond, dans des paysages, la vue de Florence et de Pistoic.

Botticelli et son protecteur, ayant été accusés d'hérésie pour ce tableau, par des artistes offusqués de leur gloire, l'Assomption fut dérobée à tous les regards. Nul ne peut dire ce qu'il en advint ensuite. On sait seulement que le tableau fut acheté par le duc Alexandre de Hamilton.

Le temps n'a pas terni l'déale fraîcheur de ce tableau. 


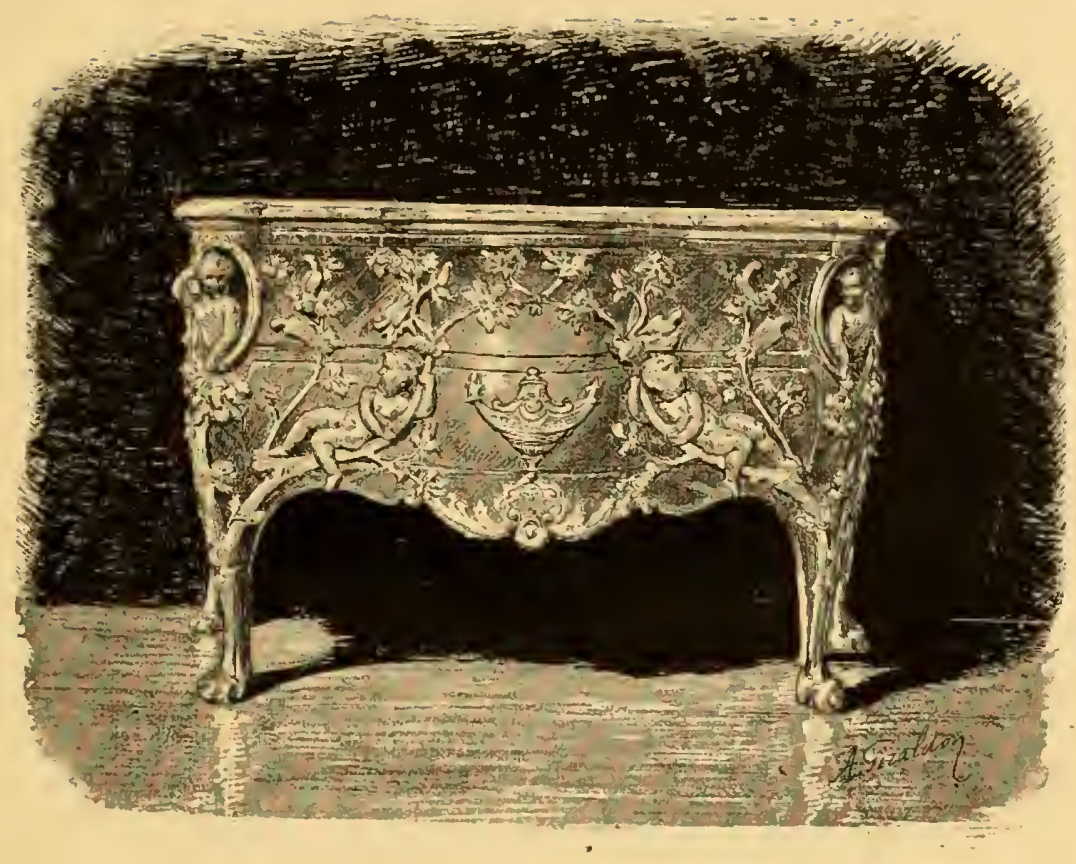

No 1806 . - Commode Louis XV vendue $162+20 \mathrm{fr}$.). 

Il semble au contraire qu'il vienne d'ètre acheré par un ange pour un décor du paradis. Les teintes sont prises aux roses de l'aurore, à l'azur du ciel et à l'or des étoiles.

C'est le point de mire de beaucoup de musées; aussi, comme pour le Giorgione, les amateurs s'abstiennent de pousser. Le combat s'établit entre le Louvre et la National Gallery; mais le Lourre hésite à 4400 guinées, malgré le crédit de cinq cent mille francs ouvert, dit-on, exceptionnellement par le ministère des beauxarts. Le musée anglais remporte la victorre à I 24200 francs, et des bravos enthousiastes, pour saluer ce triomphe, éclatent dans la salle.

La Circoncision, magnifique tableau d'autel de Lucas Signorelli, l'un des précurseurs de Michel-Ange, provoque encore une lutte ardente à coups de guinées entre M. Gauchez et M. Burton, mais c'est encore l'Angleterre qui triomphe à 8 i goo francs.

Sensation profonde aussi lorsque passe en vente l'Enfant rieur de Léonard de Vinci, connu sous le nom de l'Enfant à l'alphabet, la perle de la collection Fonthill, après avoir été celle de la collection Arundell. Cette précicuse peinture, léguée par lady Belly Germaine, héritière de la maison Arundell, à sir W. Hamilton, avait été achetée 34 I 25 francs en 1 So I, à la vente de ce dernier, par MI. Beckford. Lors. que celui-ci fit sa vente à Fonthill-Abbey en i 825 , il la racheta de nouveau 25850 francs et la replaça dans son palais d'Écosse. En I 882 , elle passe entre les mains de M. Winckworth pour 57330 francs. 
Un splendide portrait de Philippe IV debout, en costume noir et en culotte bouffante, portant l'ordre de la Toison d'or et tenant à la main un papier sur lequel se trouve inscrit le nom du grand Espagnol - Velasquez! - Le catalogue croit devoir indiquer l'origine de cette peinture prise à Madrid pendant la guerre par le général Dessolle, achetée à sa fille par M.Woodburn et venue ensuite à Fonthill. Nous le voulons bien. Cependant le musée de Madrid ne nous paraît pas si dépossédé que cela. Il y avait donc un stock de Philippe IV en Espagne, car on peut en voir encore un sorti de ce pinceau merveilleux, et comme celui de la vente Hamilton, très vivant et très librement posé.

Ce tableau donne licu à une lutte épique entre M. Burton, M. Gauchez et M. Arnot, un Américain enthousiaste, à coups de guinées.

$3000 ! 4000$ ! 5000 guinées! Ainsi jusqu'à 5500 guinées, où le combat se circonscrit entre la National Gallery et le Louvre. Les deux musées couvrent alternativement les enchères l'un de l'autre par 50 guinées jusqu'à 6000 , où, battus et impuissants, nous sommes obligés, à notre grand regret, de nous retirer du combat, pour laisser nos adversaires remporter la victoire à ce prix considérable que jamais portrait de Velasquez ait atteint : 162000 francs! Mais ce n'est pas encore ce que les portraits de Gainsborough atteignent chez nos voisins, passionnés pour leur peintre.

Rien ne les arrête, ces Anglais. L'argent est peu lorsqu'ils veulent. Cela date de loin. En i 828 , l'ambassadeur d'Angleterre, visitant l'hôtel de Cluny, se 


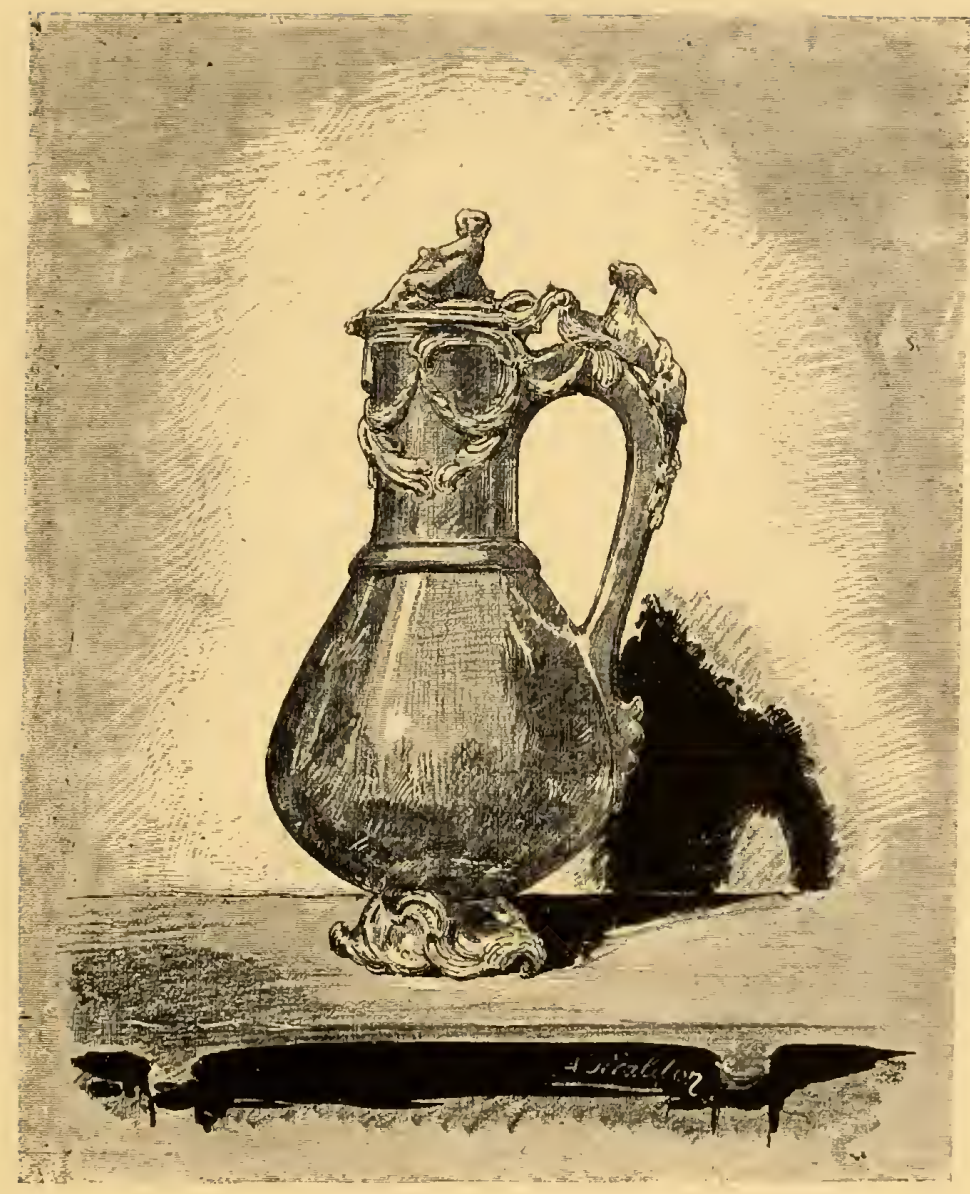

$N^{\circ} 488$. - Aiguière en jaspe (vendue $\dot{6}_{+}{ }^{1}+\circ \mathrm{fr}_{\circ}$ ). 

trouva tout émerveillé de cet immense entassement de tant de choses :

- Monsieur, dit-íl à l'antiquaire, remettez-moi la clef de votre maison, et l'ambassade vous compte 600000 francs ce soir.

M. Du Sommerard tenait la clef entre ses mains, il hésita un instant; mais à la fin :

- Mylord, répondit-il, l'Angleterres'est déjà fait tout un moyen àge avec nos dépouilles, ilne sera pas dit que je l'aurai augmenté.

Et ils se séparèrent pour ne plus se revoir.

A méditer pour nous cet exemple de patriotisme, si nous ne voulons pas, au train dont vont les choses, être dépouillés peu à peu de tout ce que nous possédons en richesses artistiques.

Pour cette vente Hamilton, les grands marchands de tableaux de Londres ont refusé les commissions qui les auraient fait entrer en concurrence avec leurs musées. Ils ont tous sacrifié généreusement leur intérêt particulier dans la circonstance. A chaque fois que M. Burton dit à haute voix : "J'enchéris pour la National Gallery ", les Anglais applaudissent et toutes les enchères s'arrêtent respectueusement. La lutte n'a plus lieu seulement qu'avec l'étranger à partir de ce moment.

MM. Agnew et fils, les grands marchands de tableaux, dont l'un siège à la Chambre des communes, ont refusé une commission de 5000 guinées pour l'Histoire de Myrrha de Giorgione, qui s'est vendue seulement 35425 francs au Musée National.

C'est beau comme un acte d'héroïsme du De viris. 



\section{$\mathrm{X}$}

Hàtons maintenant notre marche au milieu de toutes ces enchères enfiévrées, et consacrons nos dernières lignes aux objets d'art d'une grande rareté ou d'une excessive richesse. Parcourons le catalogue, les gros totaux et les raretés excessives doivent seuls désormais nous arrêter.

Nous n'aurons que l'embarras du choix, comme Edmond Dantès en découvrant le trésor de MonteCristo. Ce sont les bustes antiques de basalte et de porphyre; les pendules de Dutertre, de Robin et de Lepaute; le miroir de Boulle, dessiné par Berain; le buste en bronze de Pierre le Grand; la coupe de cristal de roche; le lit Louis XVI, drapé de tapisseries des Gobelins; les vases de Sèvres, montés par Gouthière; les miniatures de Petitot, et tant d'autres choses sur lesquelles il est impossible de s'arrêter dans cette rapide énumération, car nous ne pouvons être que très sobre sur le choix des objets.

Parlons d'abord d'une Aiguière d'aventurine jaspée, avec anse prise dans la masse, tant le bloc précieux, dans lequel elle a été taillée, était beau. Très rare pièce byzantine du huitième siècle, montée en or mas- 
sif sous Louis $\mathrm{XV}$ par quelque riche fermier général du temps. Superbe, la monture! Partout l'or se relève en bosse. Un amour surmonte le couvercle, une chèvre grimpe sur l'anse; de délicieux ornements rocaille, de la meilleure ciselure, entourent le bec et le pied. L'orfèvre français est resté inconnu. Cependant on dirait la main de Germain, l'auteur des Éléments d'orfévrerie. Comme poinçon, un S couronné, indiquant la date précise de 1758. - Vendue 64140 francs. Acheteur Lowengard.

Provenant de Versailles, un grand canapé Louis XVI d'un charme pénétrant. La tapisserie de Beauvais, d'une exquise pâleur, prête son ton assoupli aux dorures du bois sculpté. Les guirlandes de fleurs, mêlées aux feuilles de laurier, sont admirablement fouillées. Il est difficile d'imaginer rien de plus délicat (3o 57 o francs).

Deux paires de candélabres Louis XVI, à cinq branches supportés par des vases en émail bleu, aux anses de sirènes enguirlandées de fruits et de feuillages dorés à l'or moulu : i 33744 francs. - Sont maintenant à Paris dans une collection princière.

Une splendide commode de l'époque rocaille, avec panneaux en marqueterie, où flottent des fleurs et des fruits. Elle porte le chiffre royal sur la serrure. Adorable cette commode, palsambleu! Les lignes vont, viennent, courent, s'évident, se tourmentent dans un fouillis déconcertant, avec une pointe de raffinement qui n'est pas sans saveur. On dirait voir les petits maitres de l'époque, le tricorne sous le bras, la main au jabot, le 


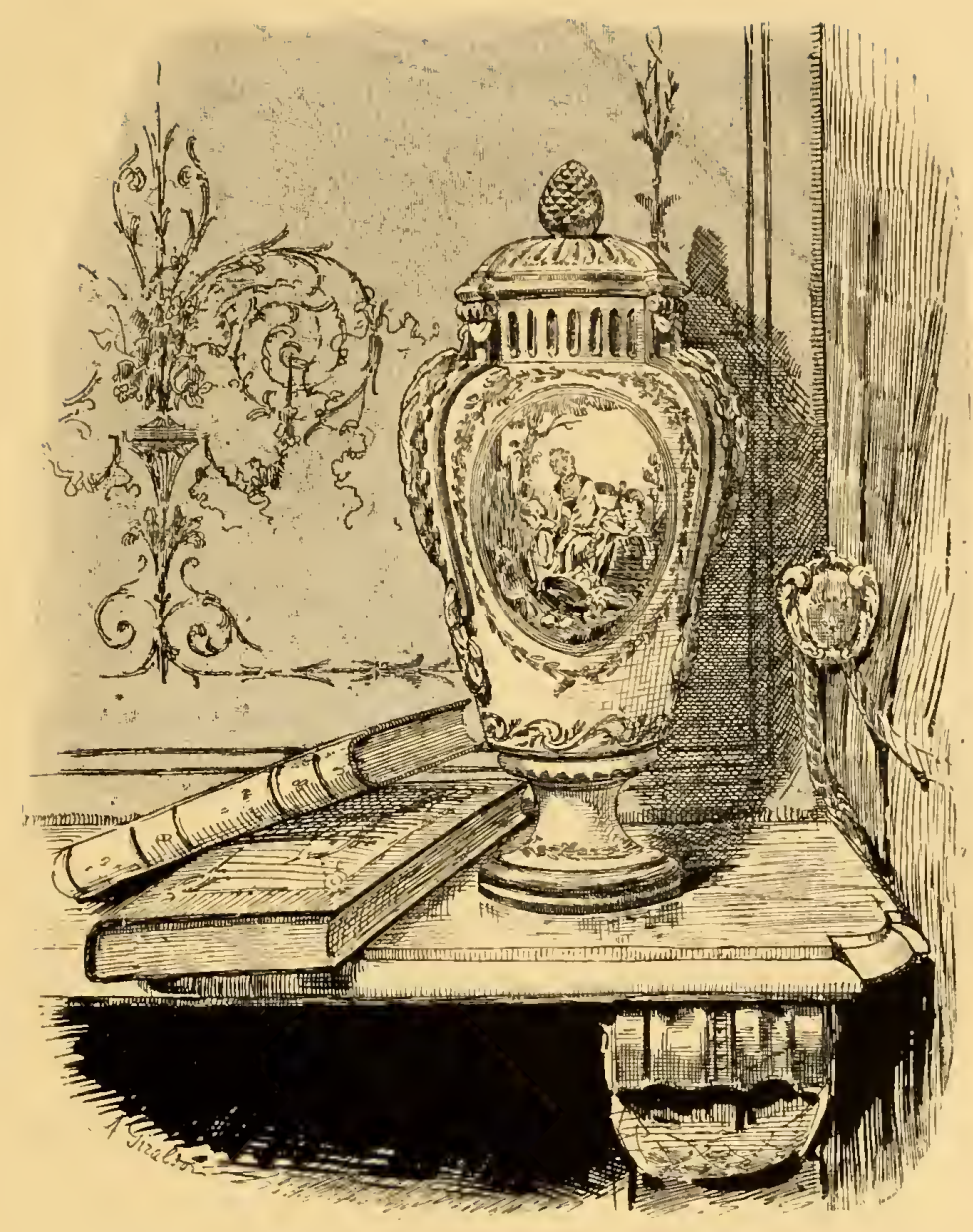

N॰509. - Vase de Sèvres (vendu 4I 2 Io fr.). 

dos courbé pour faire un compliment. C'est un vrai madrigal! La lumière caresse ces surfaces ondulées, et produit de charmants clairs-obscurs. Elle provient de cette vente du mobilier de Versailles, si bien décrite par le baron Daviller, et qu'il faut lire dans sa préface du Catalogue du duc d'Aumont. M. E. Joseph l'achète 83480 francs.

Un I Tase en rieux. Sèrres. Sur un fond bleu se détachent des filets or et blanc, des ornements variés et des guirlandes de feuillages. Au centre, un médaillon avec une scène champêtre; une fermière de Boucher jouant avec ses deux enfants. Sèvres délicieux! où sont allées tes belles pièces! Devenus trop bourgeois à une certaine époque, nous n'avons pas su les conserver. Mieux avisés, les Anglais ont formé, avec ces délicates poteries, la collection fashionable par excellence. Ce n'est plus à leur pesant d'or qu'ils les payent aujourd'hui, c'est bien davantage. Aussi, vivement disputée, cette pièce atteint-elle le prix relativement élevé de 412 ro francs.

Deux Armoires de neuf pieds de haut, exécutées par Boule, sur les dessins de Lebrun, en ébène et en incrustations de cuivre et d'écaille de tortue. Première et deuxième partie, c'est-à-dire que sur l'une l'écaille forme le fond de la marqueterie, et sur l'autre le cuivre. Des bronzes superbes en ronde bosse, mascarons, figures allégoriques, se détachent sur les panneaux de devant. Deux amours, modelés de main de maître, voltigent au sommet. Des arabesques fuyantes et entrelacées ornent les deux corps. Le bois 
et l'écaille se marient si heureusement dans ces armoires qu'ils tempèrent la chaleur brillante des dorures. C'est du Louis XIV majestueux pour les opulenciers de notre époque.

"Elles étaient autrefois au Louvre ", dit ironiquement le catalogue. Est-ce bien sûr? et il ajoute aussi qu'avant elles faisaient partie de la collection du duc d'Aumont. J'aí voulu les retrouver avec leur description au catalogue de cette vente, faite le 12 décembre $1782,-$ mais vainement.

Malgré cela, 3 I $2_{2} 950$ francs les deux armoires! A S. Wertheimer, déjà nommé, le richissime marchand de Bond-street! Nais notre amour-propre national est sauf. Nous avons mieux. La grande armoire qui fait au Louvre l'ornement de la salle des dessins italiens est autrement belle. Consolons-nous.

Sur le Cartonnier du duc de Choiseul, se dresse une charmante pendule d'Allard. Que de dossiers curieux, d'aveux terribles et de dénonciations sanglantes, il a dû renfermer ce meuble précieux, dépositaire des secrets d'État, alors qu'il était possédé par celui que la Du Barry faisait sauter sous la forme d'une orange. Il avait jadis pour voisin, dans le cabinet du célèbre ministre, un magnifique bureau d'apparat, aujourd'hui a Vienne, au palais du prince Richardde Metternich, une véritable merveille d'ébénisterie et de ciselure, dont il a refusé d'un de ses amis 300 ooo francs.

Après une passe d'armes très brillante, où M. Wertheimer faut des efforts inouis pour triompher, ce spécimen précieux de notre art national est adjugé 


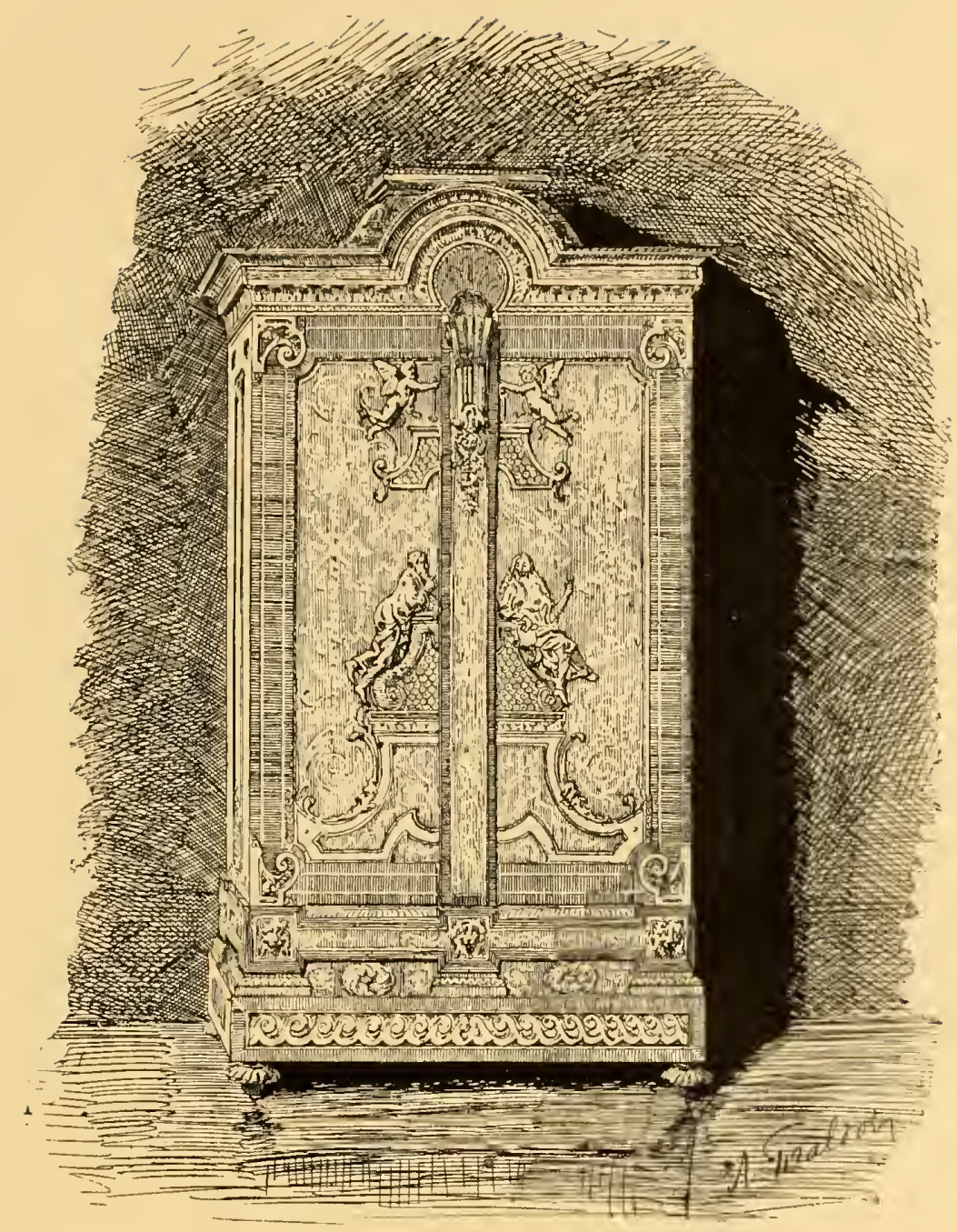

No 672. - Armoire de Boule, dessinée par Lebrun (vendue avec son pendant 3 r 3950 fr.). 

I +4690 francs aux commissionnaires MLI. P. et D. Colnaghi, de Londres.

Ce bureau de travail ira très probablement à Chantilly, dans une hospitalière collection, où nous pourrons tous le retrouver et l'admirer de nouveau.

Une liguiere persane du quin-ieme siècle, d'une forme exquise, en verre émaillé et doré. Autour du col, des arabesques et des filets entrelacés. Sur la panse à fond bleu, des cavaliers émaillés d'or et de couleur. Le baron Adolphe de Rothschild qui a, dans son hôtel du parc Monceau, les plus belles choses de cette époque, avait jeté son dévolu sur cette pièce. Il la pousse jusqu'à 7 I 000 francs, prix auquel ses concurrents lui laissent le champ libre.

Une Saliere et une Conpe,deux types de cette faïence rare et mystérieuse, successivement baptisée, faute d'en connaître l'auteur, faience Henri ll et de Diane de Poiticrs, dite d'Oiron par Benjamin Fillon, œurre enfin, selon les autres, d'un descendant de Lucca della Robbia, attiré à la cour de France à cette époque.

Ces deux pièces méritent qu'on leur consacre quel. ques lignes.

En 1859 , le duc Hamilton avait acheté 2000 francs l'une, et 7000 francs l'autre.

La Saliere de quatre pouces de haut, affecte la forme hexagone déjà connue, avec des colonnes entre lesquelles se tiennent, dans des carités, trois figures d'Amours assiss dos à dos et les bras entrelacés. Au pied du socle une rangée de mascarons.

Adjugéc 22000 francs à M. Attenborough. 
La Coupe, d'un caractère très pur, a quatre pouces de haut sur cinq et demi de diamètre. Elle est un peu semblable à celle du Louvre, avec des entrelacs couleur de cuir, gaines, arabesques, monstres marins et branches de laurier. A la base, des découpures en ogive, des consoles à mascarons, des coquilles et des mufles de lion. Un médaillon porte les trois croissants de Henri II entrelacés, la pointe en dehors : ce sont là les lettres initiales redoublées du nom de Catherine de Médicis, et non la devise de Diane de Poitiers, suivant la version fausse généralement accréditée.

Merveilleuse, délicate, fine et belle comme une cuvre de Cellini, cette coupe passe par les soins de MM. Rollin et Fenardent dans la collection Spitzer pour 30668 francs. Félicitons-le de faire rentrer la fugitive dans sa patrie.

Que nous sommes loin de l'époque où Fiorentino fit événement, en racontant dans son feuilleton que M. de Rothschild venait d'acheter 20000 francs au compositeur Strauss une aiguière de cette faience mirifique avec les armes de Montmorency-Laval sur le couvercle. Cela vaudrait trois fois plus aujourd'hui.

Reposant sur un pédicule, une table-échiquier, de fer damasquiné, ornée de bronze doré, de figures d'argent et de plaques de lapis-lazuli. Faite en i 5 40 environ et offerte au prince de Savoie par le duc de Milan.

Achetée 3000 guinées $(81000$ francs) par M. Beckett Denison, battant son concurrent, M. Lowenstein.

Elle renait de la vente Debruge Duménil, puis de 


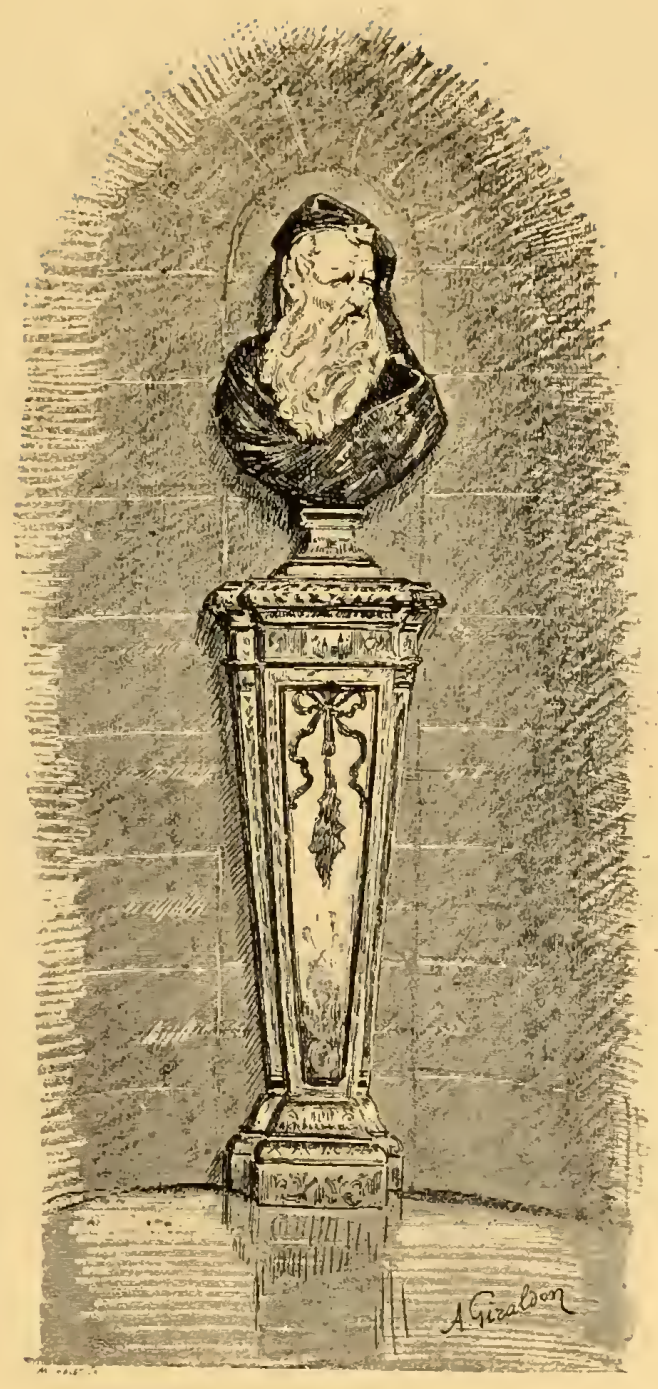

$N^{\circ}$ Ioo3. - L'Hiver : Buste en falence de Rouen

(Les Quatre Saisons, vendues $68800 \mathrm{tr}$.). 

celle du prince Soltikoff, où le duc Hamilton l'avait payée $20000 \mathrm{fr}$. A cette même vente, le miroir de travail identique qui accompagnait cette table avait été payé 30500 francs. On peut le voir au musée de Kensington.

Quelques mots des émaux maintenant.

Une tasse et son couvercle racontant les amours de Samson et de Dalila; émail signé : JoHrinves penı. C.Mud junior, 1539,54600 francs à M. T.-M. Whit. head.

Un triptyque en couleur par Pierre Raymond, représentant la Mort du Christ 3 I 608 francs à M. Wareham.

Une plaque carrée en grisaille: l'Adoration des mages, Penicaudi mantu, $3+528$ francs à G. Attenborough.

Un autre triptyque par Nardon Pénicaud, émail à paillons et à reflets métalliques : la Descente de croix, la Mise au tombeau et la Résurrection. Acheté jadis à la vente Fonthill to5o francs; 45865 francs à M. G. Attenborough.

Bien curieux ces quatre bustes des Saisons, symbolisant les âges de la vie, pris dans leur gaine, et sortis de la fabrique du célèbre potier Vavasseur, de Rouen. Rien ne peut rendrel'effet puissant de ces beaux socles décorés de guirlandes de fleurs et se mariant à merveille avec les figures de grandeur naturelle. L'Automne et l'Hiver, avec leurs belles barbes blanches soulèvent un enthousiasme général.

Il y a quarante ans, le duc de Hamilton acheta ces 
bustes, alors au nombre de cinq, à Paris, à l'hôtel Bullion, où ils furent vendus 1400 francs. Gardant pour lui les Saisons, il donna alors l'Apollon et son support au South Kensington Museum. C'est aujour d'hui l'un des ornements de la galerie des faiences de ce palais.

La National Gallery avait résolu de les enlever à n'importe quel prix. De son côté, le ministère des beaux-arts français était animé de la même résolution. Après une bataille en règle, les quatre bustes de Vavasseur sont adjugés 68800 francs à M. Gauchez. C'est à nous! On les mettra au musée céramique de Sèvres ou dans la galerie d'Apollon au Louvre.

Une commode Louis $\mathrm{XV}$, d'un ton gai, en marqueterie de ce bois des Iles, l'orgueil des meubles rocaille. Avec ses formes ventrues, elle semble contournée comme l'échine d'un courtisan. Sur l'entablement une tablette en marbre brocatelle. Sur le devant, se détache luxuriante une belle garniture de bronze massif ciselé et doré. Ce sont des branches de chêne dont la tige part des pieds du meuble et se disperse en espalier, comme des lierres sur la façade d'une maison. Du milieu des feuillages sortent avec grâce deux adorables enfants, tandis qu'à l'extrémité des rinceaux se reposent de charmants oiseaux. Deux cariatides, des Amours en haut relief, forment les angles du meuble. C'est une idylle champêtre en bronze. Malheureusement l'entrée de la serrure ressemble trop à la lampe antique des vestales et gâte un peu le meuble. Des ves. tales! sous Louis $\mathrm{XV}$, où tout ressemble, en y regar- 
dant de très près à une robe retroussće ou à des jupons défaits. De la vertu antique dans ce meuble où le bronze s'amincit, s'échappe, se déhanche, se tord en d'adorables caprices et dans une lascive rolupté comme des pamoisons de duchesse. Voilà un véritable anachronisme. Quoi qu'il en soit, il y a amateur pour le chiffre coquet de $162+20$ franes.

Deux commodes d'ébène à huit tiroirs. Incrustations aux angles en cuivre gralvé et métal blanc avec feuillages dorés. Frontons et tiroirs formés par des plaques de laque or et noir. Pieds, bordures, entrées de serrure merveilleusement ciselés. 3000 guinées: SI ooo francs.

Un secrétaire droit Louis XVI, svelte, élancé, en acajou et mosaïque d'un rare fini. Sur le panneau qui doit s'abattre sont jetés, au milieu d'un fond quadrillé de bois ondés et satinés, des emblèmes variés : la tête d'Apollon, des corbeilles de fleurs et des instruments de musique. Porte à deux battants dans le bas, couverte de marqueterie. Aux deux angles, des chutes superbes de bronze tombant jusqu'à terre. $36590 \mathrm{fr}$.

N'oublions pas de citer encore trois meubles aux cuivres ciselés d'une façon artistique par l'enchanteur Gouthière - trois admirables choses! Arec un parrain conme celui-là, l'enthousiasme ne devait plus s'arrêter. Vous allez en juger.

D'abord un cabinet d'ébène, couvert de plaques de laque noir et or, et sur le devant, encadré de guirlandes, un grand médaillon ciselé en bas-relief : le Sacrifice d'Abraham, inspiré par Clodion, si ce n'est 
pas de Clodion lui-même. Aux angles, comme consoles, des Victoires d'une forme svelte, ciselées avec une incroyable grâce, et remontant par des lignes habiles jusqu'à l'entablement. Les frises et les poignées formées par des satyres, des enfants, des Amours, des oiseaux et des fleurs en haut-relief. Pieds d'une finesse hardie. Il règne dans cet ensemble une harmonie douce, tranquille, pénétrante. M. Wertheimer n'hésite pas à payer ce meuble $1_{4} 1960$ francs.

Ensuite un secrétaire semblable en tous points, mais portant dans la frise le monogramme de MarieAntoinette entouré de feuillages de bronze superbement fouillés. L'art est décidément un grand personnage, et Schopenhauer a eu raison de dire : "Reste debout devant lui, découvert, et attends patiemment qu'il daigne t'adresser la parole. "Il a parlé cette fois, et il a demandé à M. Davis la somme colossale de 245700 francs, qu'il s'est empressé de lui accorder. C'est le prix le plus élevé obtenu jusqu'ici pour un meuble dans une vente.

Enfin, la commode de laque, la perle de la vente! presque semblable au secrétaire, avec la grâce des détails du cabinet. Des colombes se becquètent sur le vieux laque, tandis que sur la frise des fleurs et des rubans entourent en haut-relief les deux lettres M. A. entrelacées. Une tablette de marbre noir sur le dessus attriste ce meuble, pressentiment peut-être des jours sombres qui vont arriver après la folle ivresse. Lutte ardente entre MM. Boore, Davis et Wertheimer, mais la victoire ręste à ce dernier, au même prix : $245700 \mathrm{fr}$. 


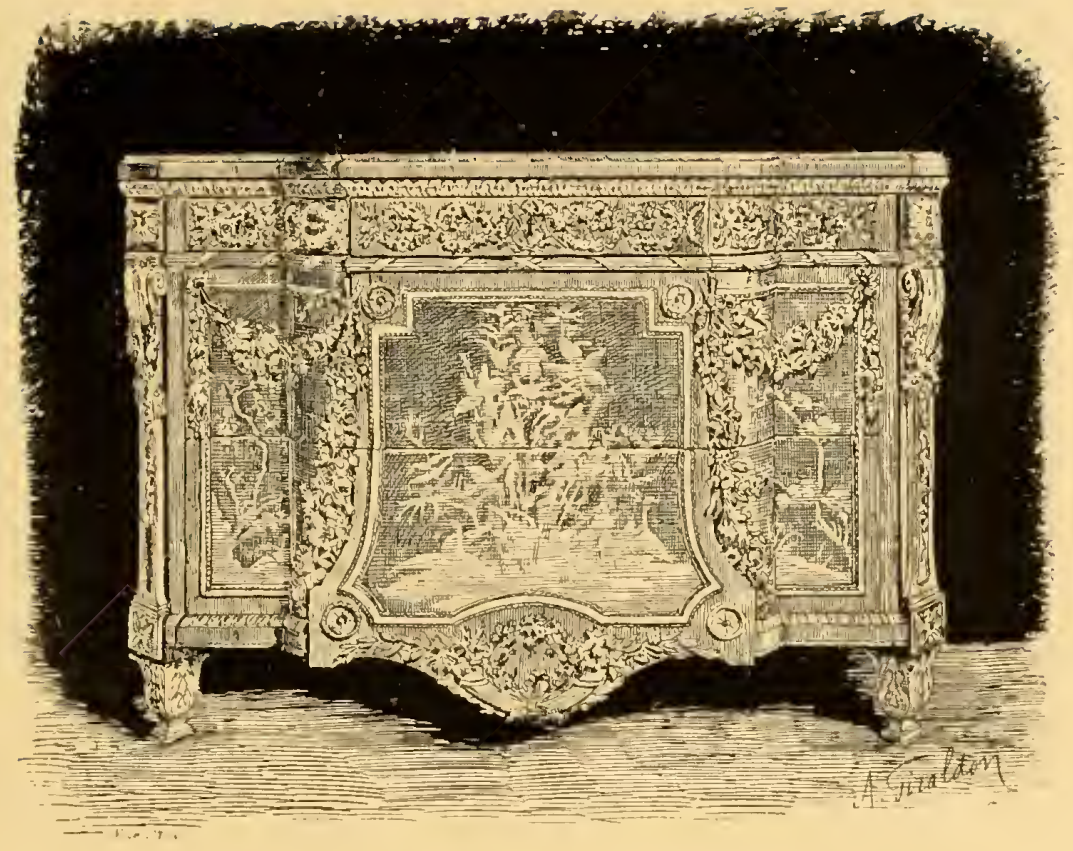

$\mathrm{N}^{\circ}$ I 298 . - Commode Louis XVI (vendue $245700 \mathrm{fr}$.). $\therefore$ 

Ces meubles merveilleux ont fait, comme disent les Anglais, la tremendous figure de six cent-trente-trois mille francs: $2+360$ livres sterlings!

L'absence sur le cabinet des initiales de la reine qui affirment si bien, par leur présence sur la commode et le secrétaire, leur authenticité royale, a empêché ce meuble d'atteindre le prix des deux autres, bien qu'il fût d'un style très pur et d'un ensemble irréprochable.

Peu de succès, par exemple, les Sèvres, qui ne sont pas en pâte tendre. Un cabaret avec ornements en grisaille sur fond d'or, offert par Charles $\mathrm{X}$ au grandpère du duc Hamilton, et daté de 1815 (une mauvaise époque), œuvre du peintre Dufey, qui a reproduit de son micux, sur quelques pièces, des portraits de Poussin, de Lebrun et de Lesueur, et sur le plateau central une Sainte Cécile d'après Mignard - n'obtient que $9^{5}$ guinées, seulement 2565 francs. Cela repose au milieu de ces gros chiffres tapageurs.

Un chef-d'œuvre encore! - Par Houdon, une statuette en marbre de Voltaire de 18 pouces de haut. Le grand railleur travaille chez lui sans doute. Il est en jabot et en culotte courte, coiffé d'une perruque et d'une sorte de bonnet. Une veste brodée passe sous une longue houppelande. Du doigt il marque, dans un livre fermé, la page qu'il vient de lire. Adjugé : 27300 francs.

Cinq statues de bronze commandées en Italie par François Ir pour la décoration de son palais de Villeroy, achetées plus tard avecle chàteau par Nicolas Neuville, 
secrétaire d'État, qui fut la tige des ducs de Villeroy. Ces statues, vendues à la Révolution de 93, furent acquises par le dixième duc de Hamilton.

M.Stettiner les achète toutes: 1'Apollon du Belvédère, 1300 fr.; la Diane, de Versailles, 13650 fr.; le Gladiateur. Borghìse, 14590 francs; l'Antinoiis du Belvédère, I 2658 francs; l'Hercule et Télèphe, I 2 too francs. - Pas cher cet ensemble! Il y a peu de temps, M. Gustave de Rothschild payait 35 ooo fr. une Diane de Pigalle qui ornait la Garenne de M. Valentin à Clisson. Une coupe de cristal de roche gravé, enrichie de turquoises en haut-relief, venant de la collection royale de France, ainsi désignée par MM. Christie, Marson et Woods - 2 I 500 francs. 


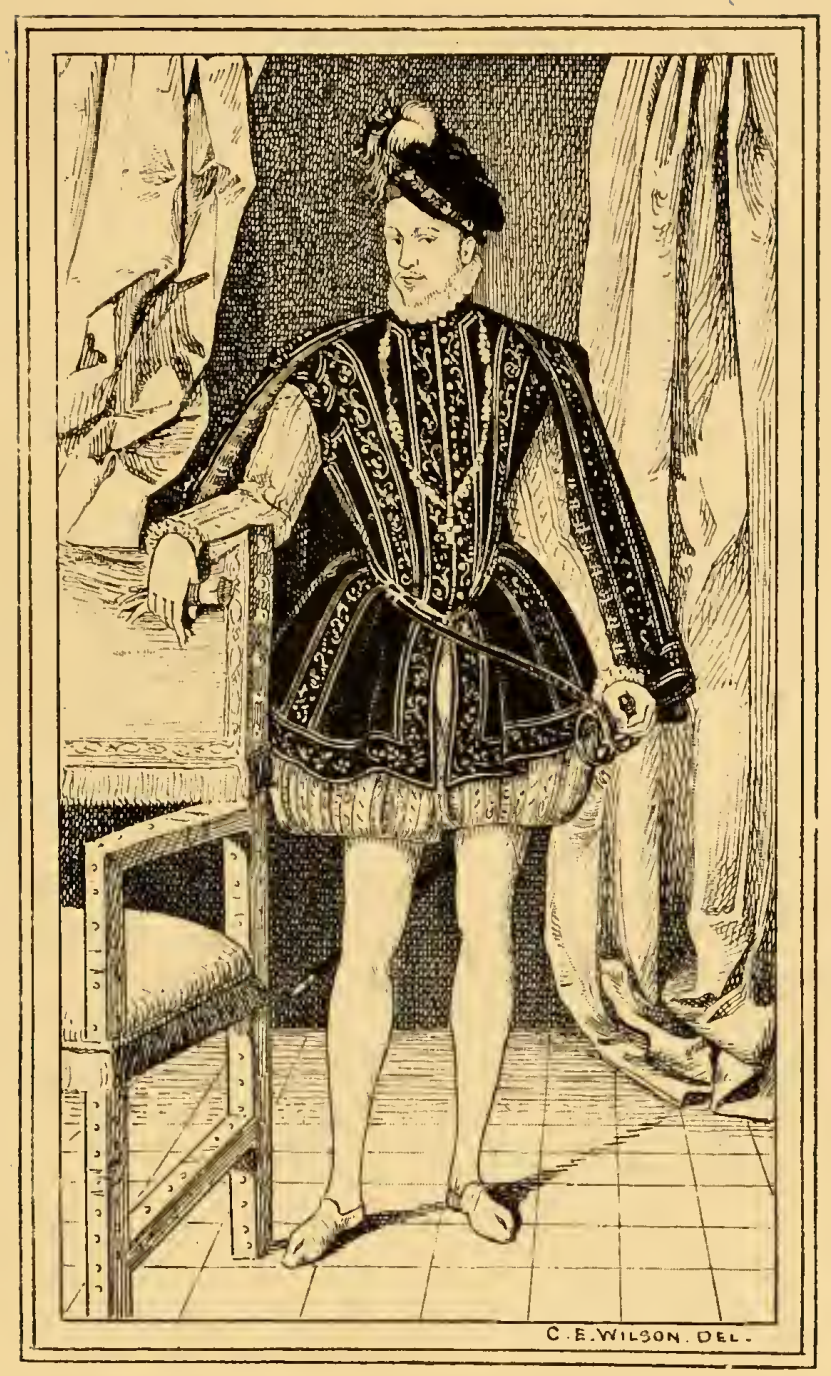

N* I65I. - Portrait d'Henri II par Janet (vendu, avec ceux d'Henri III et Charles IX, 45 710 fr.). $q: Y ?, v$ 



\section{I}

Parmi les deux cents miniatures peintes sur vélin, carton et iroire, qui forment une vacation tout entière, les Petitot ont les honneurs de lal journée. - Rien d'extraordinaire à cela. Petitot travailla pour Louis XIV et pour Charles I ${ }^{\text {er }}$. Il fut à moitié Anglais, et répondit aux faveurs des deux monarques, comme homme de génie, en prenant le premier rang parmi tous les peintres sur émail. On sait qu'il se servait habituellement de plaques d'or. Au début, en Angleterre, il recevait 30 guinées pour chacun de ces portraits. Plus tard il osa en demander 40. 11 avait à ses ordres un peintre de talent qui reproduisait à l'huile la ressemblance de ses modèles. C'était sur ce premier travail qu'il prenait ses esquisses; puis il les achevait d'après nature. Il copia ainsi plusieurs fois la figure de Charles ${ }^{e r}$, qui voulut bien lui accorder quelques séances.

Voici le prix de quelques-uns de ses portraits présentés aux enchères deux siècles et đemi après sa mort :

Louis, Dauphin, duc de Bourgognue, l'élève de Fénelon, mort à Marly le 18 février 1712. Portrait équestre, signé, avec une inscription au dos indiquant 
qu'il provient du cabinet de Louis XVI, où il faisait pendant à un portrait de Colbert en buste et entouré de plusieurs emblèmes, 17750 francs (Joseph).

Jean-Baptiste Colbert, en costume noir, une collerette de dentelles, le collier et le ruban du Saint-Esprit, 6265 francs (W. Boore).

Jean-Baptiste Lulli, 2210 francs (W. Philpot).

$M^{\text {we }}$ de Maintenon, sur vélin, habillée de bleu foncé, avec une coiffe de dentelle noire, assise sur une chaise de velours cramoisi brodé d'or, 49 ro francs (W. Grindlay).

Louis XIV, émail rond adjugé 1850 francs à sir J. Leslie.

A noter encore toute une série de petits portraits en pied de la maison de Valois, par François Clouet dit Janet : Henri II, Henri III, Charles IX, Catherine de Médicis, le grand Dauphin et Claude de France. Ces six portraits, d'une grande finesse de touche, et, ce qui ne gâte rien, en parfait état de cunservation après trois siècles, trouvés en 93 pour rien, par M. Rattier, dans la boutique d'un parfumeur, se vendent 45710 francs à W. King.

Le Couronnement de Henri IV par Philippe de Champagne. La scène se passe dans la salle des États. Il y a vingt-cinq figures au moins dans cette miniature sur vélin. Le trône est dans un angle. Un tapis fleurdelisé d'or couvre le sol. -8450 francs (Joseph).

Terminons la série des miniatures par Jacques $I^{\text {er }}$, roi d'Angleterre, peint par N. Hilliard, en costume de soie lilas broché d'or, avec une collerette de dentelles. 


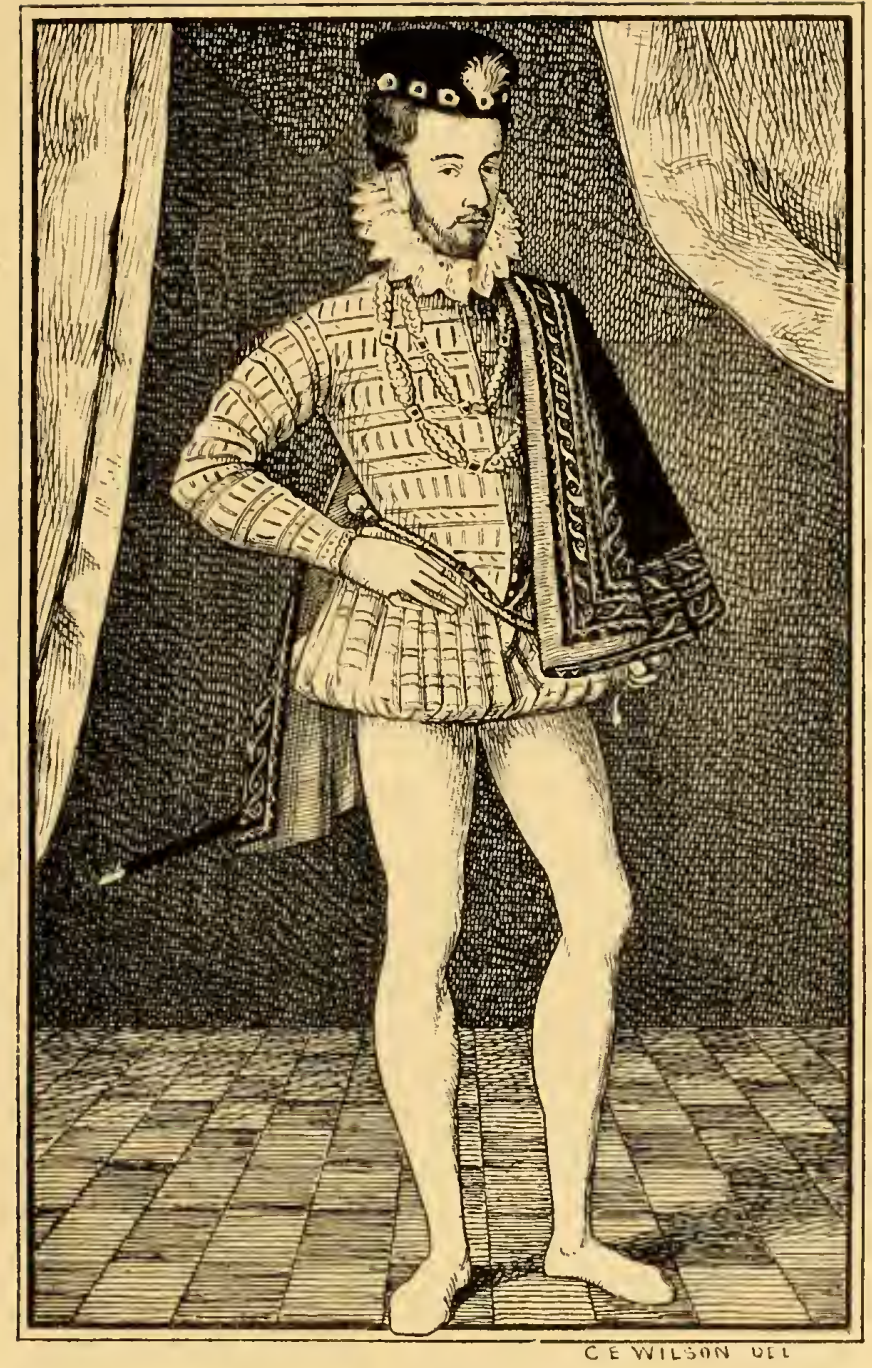

No 165 r. - Portrait d'Henri III par Janet (vendu, avec ceux d'Henrı II et Charles IX, 45710 fr.). 

Précieusement conservé dans un écrin du temps émaillé, avec le chiffre royal en brillants. Après une lutte courte, mais très animée, entre deux compétiteurs acharnés, M. King et M. Joseph, ce portrait est adjugé au prix fabuleux de 737 го francs au dernier, un marchand de Bond-street.

Que les temps sont changés! En 1842 , un portrait de la reine Élisabeth se vendait 14 livres! Cet Hilliard, dont les Anglais sont si passionnés, était bien quelque peu prétentieux. Il disait en parlant de lui-même : - J'ai imité dans la perfection le genre d'Holbein pour peindre " en miniature. " Comme il est loin d'avoir son naturel! ses ouvrages sont pâles et manquent de variétés dans les teintes. Les bijoux et les ornements, exprimés par des lignes, sont grêles comme des cheveux. Il ne peut guère être estimé que par la reproduction fidèle qu'il a laissée des costumes de l'époque. -737 10 francs une miniature de lui : c'est raide!

A la vacation où se dispersent les monnaies grecques et romaines, les camées et les intailles antiques, se trouve le cruitistone dollar, pièce de mariage de Marie Stuart avec lord Darnley, encadrée d'un cercle de bois provenant d'un if sous lequel la tradition affirme qu'elle s'est assise. - Très habile le rédacteur du catalogue. Si non è vero, è bene tronato. Un amateur passionné, qui pousse un peu loin la religion des souvenirs, le comte de Moray, se fait adjuger cette pièce pour 440 francs. 



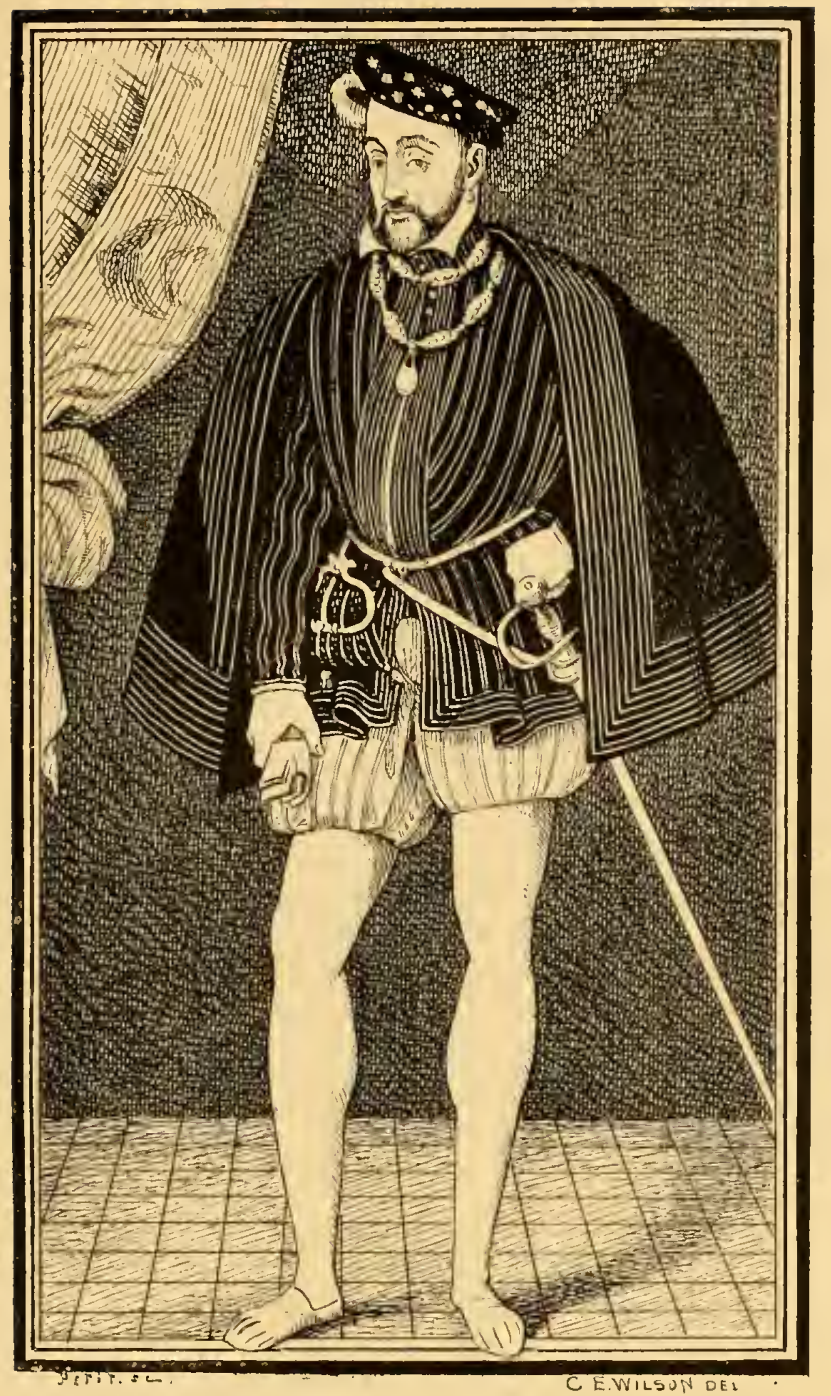

No I651. - Portrait de Charles IX par Janet (vendu, avec ceux d'Henri II et d'Henri III, 457 I $0 \mathrm{tr}$.). 



\section{II}

Et c'est ainsi qu'après dix-sept jours de bataille, au milieu d'une foule houleuse d'amateurs et de marchands, s'achève la vente la plus importante du siècle!

Toutes les vacations réunies forment un groupe de I 336612 francs, sans comprendre la bibliothèque, dont la vente, suspendue à la lettre F, ne sera reprise qu'au mois de décembre.

Avouons-le, c'est beaucoup moins qu'on ne l'avait supposé et beaucoup plus cependant que tout ce qui avait été obtenu jusqu'ici.

L'Angleterre doit être satisfaite : elle gardera presque tout. La "National Gallery » seule a largement opéré. Les délégués des musées de Madrid, de Munich, de Dresde, de Copenhague et de Saint-Pétersbourg n'ont rien acheté. La France s'est tenue sur une grande réserve : il le fallait. L'insuffisance absolue des ressources du Louvre ne lui permettait pas de lutter contre les budgets artistiques des autres pays.

Chaque vente débute par un enthousiasme, et finit par une réaction; l'admiration, à force d'être tendue 
se détend. La vente Hamilton, pas plus que ses devancières, n'y échappe en ce moment. On critique ferme. Cette oraison funèbre est dans la marche ordinaire des choses.

Nous restons, nous, émerveillé, et nous ne pouvons que féliciter ceux qui ont acheté. Ces occasions-là ne se retrouvent pas deux fois dans la vie. Heureux ceux qui en ont pu profiter!

Cependant nous protesterons contre le mauvais goût du catalogue, louant tout un peu trop éperdument, contenant de nombreuses erreurs d'attributions, et surtout illustré par des photographies économiques souvent mal "venues. Ce volume, qui ressemble trop aux dispositifs des docks pour la vente des cotons et des cacaos, est cependant déjà épuisé, ce qui prouve un désir général de la part des amateurs de conserver trace de cett grande épopée. Mais il fallait, pour donner satisfaction au public, faire à cette collection les honneurs impérissables d'un beau livre, charger des artistes en renom de graver des bois ou de reproduire par l'eau-forte les tableaux les plus appréciés. C'écait même un devoir impérieux à remplir vis-à-vis de l'art. L'exemple du prince Demidoff à San-Donato, en I 880 , devait être suivi. Agissant en grand seigneur, il avait fait vendre son catalogue illustré cent francs, au profit des pauvres de Florence. Il est à souhaiter qu'une publication soignée de cette réunion de chefs-d'œuvre se fasse; mais vous pouvez en être persuadés, ce sera la France qui s'en chargera sans doute, et non l'Angleterre. Pendant qu'on dressera des bordereaux là- 


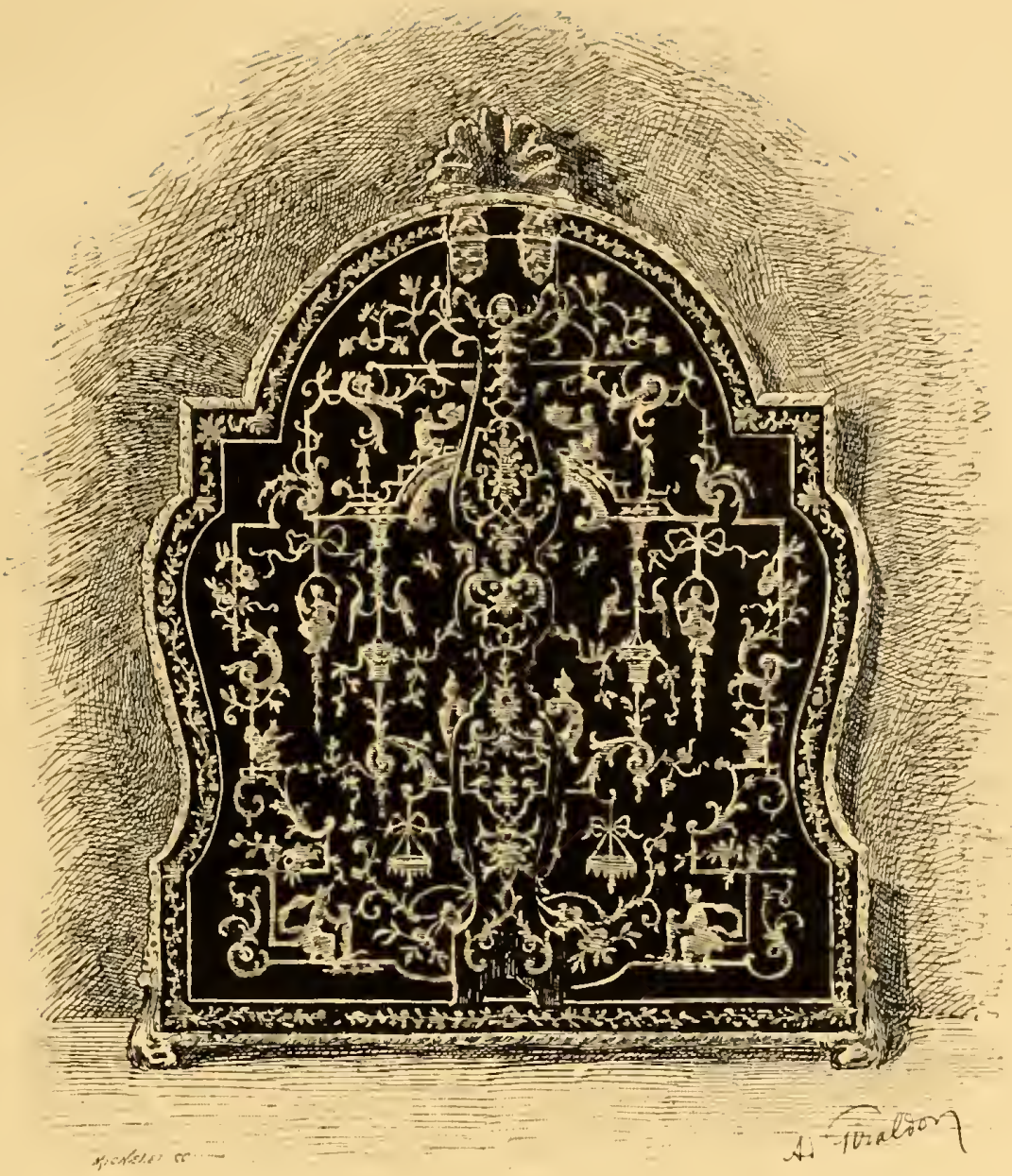

N`998. - Glace de toilette Louis XIV, par Boule d’après Bérain (vendue $95_{t^{2}} \mathrm{fr}$.). 

bas, on dessinera chez nous. Notre confrère l'Arl a commencé cette artistique besogne. Nous ne pouvons que l'en féliciter'.

Quoi qu'il en soit, un fait considérable se dégage de cette vente : la recherche par l'étranger des objets d'art français. Dans ce culte du passé, un intérêt très vif s'attache surtout à nos meubles et leur produit général, à la vente Hamilton a dépassé certainement six millions.

Soyons fiers, chez nous, aux siècles derniers, les artisans ont été sourent des artistes. Pendant cette belle époque, l'art ne dédaignait pas de descendre dans les plus humbles ateliers. Des mains des ciscleurs, des tapissiers, des verriers, des potiers, des serruriers sont sortis des monuments qui prennent peu à peu une place considérable dans l'histoire de l'art.

Cette rente met surtout au premier rang: Boule, Riesner et Gouthière. N'est-ce pas le cas, en terminant de dire quelques mots de ces maîtres ornemanistes d'une si grande habileté.

André-Charles Boule, né en 1642 , travaillait pour la cour. Il fit de l'ébénisteric un art auguste et sévère digne de rivaliser avec les plus belles lignes de l'architecture. Il était le collègue de l'orfèvre Claude Ballin et l'architecte Mansard fut son ami, on ajoute même souvent son collaborateur anonyme.

Les Gobelins furent créés sous sa direction et celle de

I. Le catalogue illustré avec les.prix vient de paraître à la librairie de l'Art, 33, avenue de l'Opéra, sous le titre: The Hamilton Palace collection Illustrated priced calalogue. 
Ch. Lebrun pour fabriquer outre les tapisseries, les meubles et les grands ouvrages d'orfèvrerie.

Louis XIV lui avait donné en 1672 un logement aux galeries du Louvre avec un brevet le qualifiant d'architecte, peintre, ciseleur, marqueteur, artiste ébéniste, inventeur de chiffres et sculpteur en mosaïque.

Le chevalier Bernin, pendant son séjour en France, se lia d'amitié avec lui et l'aida de ses conseils dans les dessins d'architecture qu'il fit pour la décoration du Louvre.

C'était un grand amateur d'estampes et Mariette raconte qu'il ne se faisait pas une seule vente où il ne fût et où il n'achetât souvent sans avoir de quoi payer. Il possédait un magnifique recueil de dessins d'habit de théâtre fait par La Belle, un manuscrit de 'Rubens, et un recueil des cent portraits de Van Dyck où toutes les épreuves étaient retouchées par la main de cet habile peintre. Malheureusement le feu prit dans l'atelier où il conservait ses curiosités et détruisit presque tout.

L'expert Gersaint, l'ami de Watteau qui mourut entre ses bras, a mis dans la préface de l'un de ses catalogues de vente en parlant de Boule : "Jamais on n'a travaillé avec plus de goût, plus de soin et plus d'honneur que lui." Et cependant la chronique du temps raconte qu'après avoir servy des Roys et des hommes riches, il mourut en $I 732$, aux galeries $d u$ Louvre, assés mal dans ses affaires.

Les grands artistes de ce temps-là, épris de leur art. 


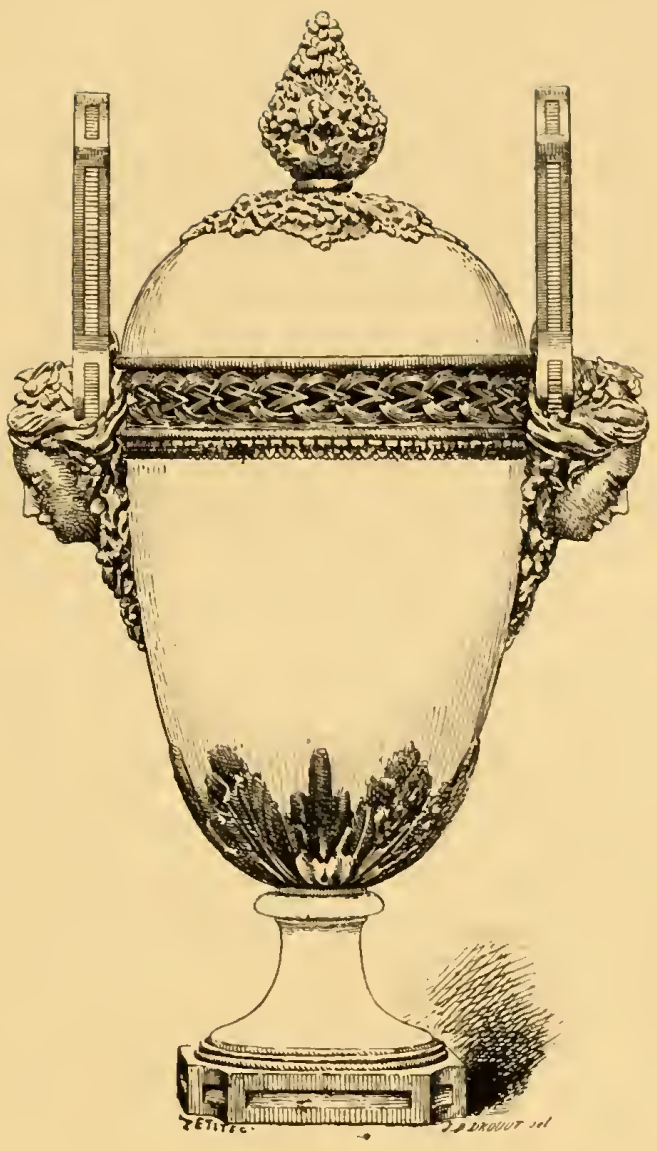

N०5o3. - Vase de Sèvres (vendu $7500 \mathrm{fr}$.) 

moins soucieux de faire fortune que de bien faire, finissaient presque toujours ainsi.

Riesner et Gouthière, ces deux collaborateurs, personnifient le goût français sans rival dans le monde entier, à la fin de ce siècle qui eut, au point de vue de l'art, toutes les splendeurs d'un soleil couchant.

L'ébéniste Riesner est peu connu encore aujourd'hui, mais avec les chercheurs qui nous entourent il aura son histoire avant peu. Il fut un ornemaniste d'une grande habileté. Il avait un sentiment très vif de la forme.

Ne nous illusionnons pas. Tel contour est aussi difficile à trouver que la silhouette d'une figure.

Il y a autant de génie dans l'agencement étudié des bois et des métaux que dans l'arrangement cherché des tons les plus variés d'un tableau, et Necker avait raison de le dire à l'époque : "Le goût est en somme "pour la France le plus adroit des métiers. "

Il est certain que Riesner fut le pourvoyeur attitré de la cour; mais de cette époque les documents sur lui manquent encore. On les retrouvera. Il paraît qu'il acheta beaucoup aux ventes sous la Terreur, car le I I pluviôse an II, il invitait les amateurs à venir chez lui “ à l'Arsenal, la seconde cour, en entrant par le quai des Célestins " voir les meubles de sa fabrique qu'il avait repris, un peu partout à la Convention.

Ce fut l'époque où l'Angleterre, sans épargner ses recherches, se mit dans nos meubles - magnifiquement et à bon marché.

Pierre Gouthière, le Beau, comme on disait alors, 
prenait le titre de ciseleur et de doreur du Roy. Dès I 77 I sa réputation était faite. Jamais on n'avait porté à un si haut degré l'art de la ciselure. Rien de plus précieux et de plus fini que les bronzes pétris par lui. $\lambda I^{\mathrm{me}}$ Du Barry le chargeait de nombreux travaux pour le pavillon de Luciennes. Il était le favori de tous les curieux et le fournisseur ordinaire du duc d'Aumont. Pendant dix ans, ce dernier lui demanda les montures de ses objets les plus précieux.

Il devint si habile plus tard, qu'il présenta un jour à Marie-Antoinette une rose de bronze doré au mat si merveilleusement travaillée que la reine la prit pour de l'or ciselé.

Le baron Charles Daviller, le savant écrivain et l'aimable collectionneur, nous apprend que Gouthière avait une boutique sur le quai Pelletier, à l'enseigne de la Boucle d'or. Pendant la Révolution, il vint habiter rue du Faubourg-Saint-Martin, section de Bondy. On pourrait aisément retrouver cette maison et on devrait y mettre une plaque commémorative.

Le premier fructidor an III, deux ans après l'exécution de $\mathrm{MI}^{\mathrm{me}}$ Du Barry, il réclama au Domaine, lors de la vente des biens de cette dernière, le payement arriéré de ses mémoires de Luciennes dont le montant s'élevait à la somme modeste de 756000 livres (en assignats sans doute). Il prenait alors la qualité d'inventeur de la dorure au mat. Mais, à cette époque, Gouthière ne put se faire payer de l'Administration.

Sous l'Empire, en 1806 , le vieil artiste renouvela sa demande sans plus de succès. Agé, épuisé par l'infor- 
tune, réduit à la plus profonde misère, ses forces le trahirent; il entra à l'hôpital, et il y mourut absolu. ment inconnu.

Son fils, en 1836 , intenta un procès aux héritiers de $M^{\text {me }}$ Du Barry, admis à prendre part au milliard d'indemnité voté pour les émigrés. Sa créance fut alors reconnuc pour So ooo francs. Mais la Cour infirma le jugement sur l'appel des héritiers, et la succession n'eut à payer en somme que 32600 francs.

Ce qui vient de se passer à Londres montre que les prétentions du pauvre et grand artiste n'avaient rien d'exagéré. 

Quinze des dessins contenus dans cet ourrage ont été exécutés par M. Adolphe GIRALDON.

Les douze autres sont extraits du Catalogue de la vente Hamilton, édité par MMI. REMINGTON et $\mathrm{C}^{\text {ic }}$, directeurs de la LIBRAIRIE DE L'ART, à Londres. 






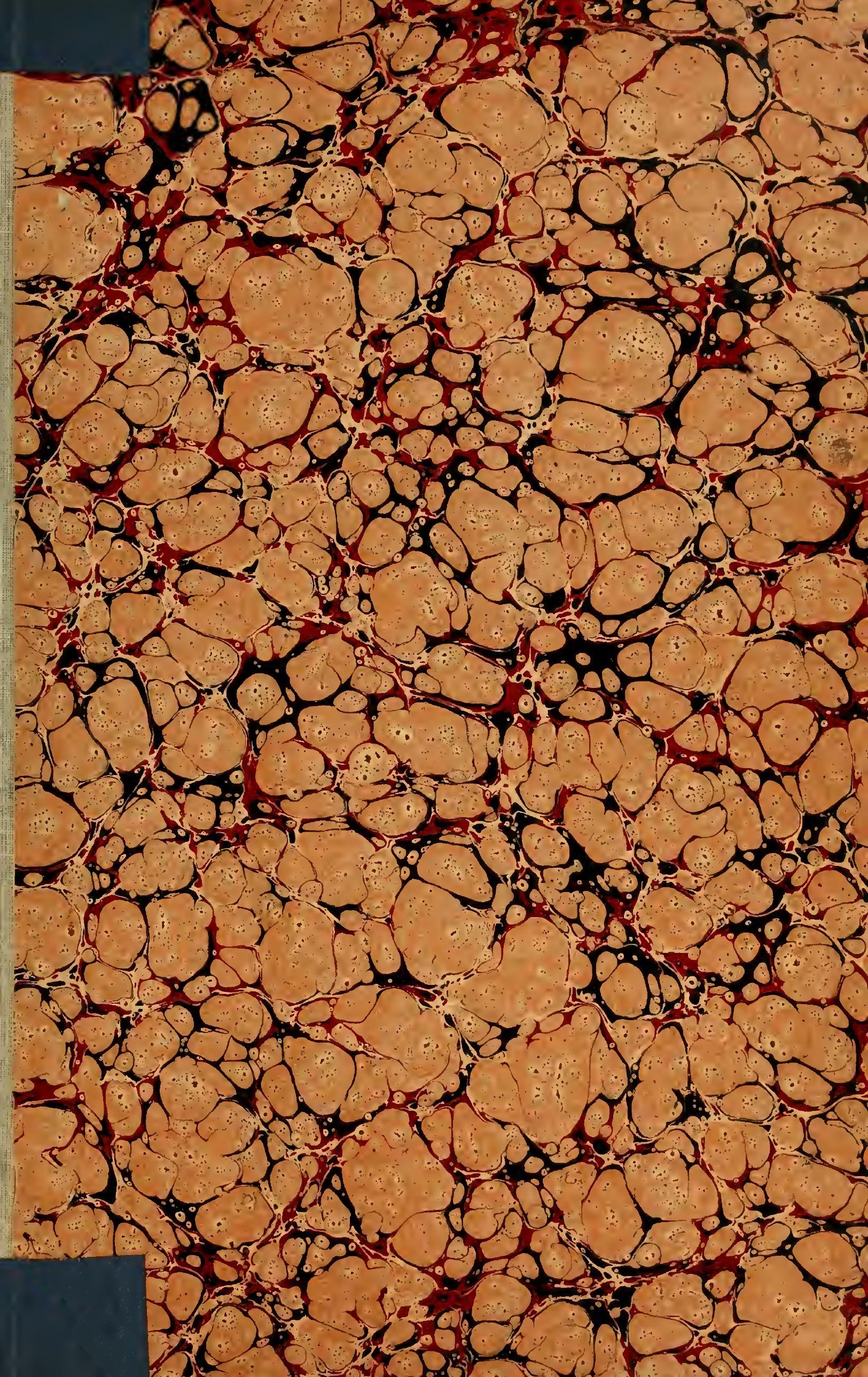


